\title{
Modeling of Filling and Solidification Process for TiAl Exhaust Valves During Suction Casting
}

\author{
Chao XIONG, Yingche $M A^{\dagger}$, Bo CHEN, Kui LIU and Yiyi LI \\ Institute of Metal Research, Chinese Academy of Sciences, Shenyang 110016, China \\ [Manuscript received 10 October 2011, in revised form 8 February 2012] \\ (C) The Chinese Society for Metals and Springer-Verlag Berlin Heidelberg
}

\begin{abstract}
Investment and suction casting (ISC) represents an economic and promising process route to fabricate automotive exhaust valves of $\gamma$-TiAl based alloys, but information available on the metal flow and the temperature changes during mould filling and solidification process for the ISC process is meager. A sequentially coupled mathematical flow-thermal model, based on the commercial finite-volume/finite-difference code FLOW-3D and the finite-element code PROCAST, has been developed to investigate the ISC process. In term of calculating the flow and temperature fields during the filling and solidification stages, potential defects including the gas bubbles and the surface air entrainment occurred in the mould filling process and the shrinkage porosities formed in the solidification process are predicted and the reasons for the formation of these defects are also analyzed. The effects of filling pressure difference control methods and moulds on gas bubble and surface air entrainment behavior are presented. It is found that by changing the filling pressure difference control methods from general suction casting to "air leakage" suction casting and reducing air leakage flow rates, the gas bubbles are eliminated effectively, and the surface air entrainment attenuate dramatically. With resort to a mould with a tetragonal runner, the surface air entrainment decrease to the lowest level. Finally, the water analogue and suction casting experiments of exhaust valves are implemented for further validation of the simulation results.
\end{abstract}

\section{KEY WORDS: Filling and solidification; $\gamma$-TiAl; Exhaust valves; Suction casting; Simulation}

\section{Introduction}

The increasing demand for improving energy efficiency and reducing pollutant emissions in automotive engines has led to serious consideration of light weight materials used for manufacturing exhaust valves $^{[1-4]} \cdot \gamma$-TiAl based alloys are strong candidate for such an application owing to their low density, high specific strength and stiffness, high temperature strength retention, and good oxidation resistance ${ }^{[5-7]}$. In comparison with the various valve manufacturing technologies which include thermo-mechanical processing and powder metallurgy, investment casting is regard as the most economic processing technology with high precision ${ }^{[8,9]}$. In addition to the merits of investment casting, the advantages of ISC encompass better filling of castings, finer as-cast grain size,

\footnotetext{
† Corresponding author. Assoc. Prof., Ph.D.; Tel: +86 24 23971986; Fax:+86 24 23906716; E-mail address: ycma@imr.ac.cn (Yinche MA)
}

DOI: 10.1007/s40195-011-0503-0 reduced inclusions and much-improved working conditions $^{[10,11]}$, so ISC represent a promising process route to produce automotive exhaust valves of $\gamma$-TiAl based alloys.

The metal flow and the temperature changes during mould filling and solidification processes are undoubtedly important for the quality of castings in the suction casting process. Kashiwai et al..$^{[12]}$ utilized $\mathrm{X}$-ray radiography to directly observe the mould filling of the vacuum suction casting processes of the aluminium casting alloy $\mathrm{AC} 4 \mathrm{C}$, which were carried out at two different suction pressures and three different decompression rates. It was found that the higher the suction pressure and decompression rate, the more turbulent the free surface of molten metal, giving rise to earlier occurrence of gas entrapment, larger volumes of entrapped gas and higher risk of misrun. Giese et al. ${ }^{[13]}$ conducted a series of vacuum suction casting experiments of an A206 Al-based alloy rectangular plate to study filling and solidification characteristics, to monitor filling rates under a variety of suction pressure profiles. Experimental results 
also showed that the effect of the suction pressure profiles on the mould filling behavior were significant. However, an exhaustive literature search indicates that the only meager details of information regarding the metal flow and the temperature changes during the mould filling and solidification processes in the suction casting process have been supplied until now.

Since numerical simulation not only gives an insight to the mould filling and solidification processes during a wide variety of casting but also reduces casting cost and shortens preproduction cycle ${ }^{[14-16]}$, a sequentially coupled mathematical flow-thermal model, based on the commercial finite-volume/finitedifference code FLOW-3D and the finite-element code PROCAST, is developed to investigate the ISC process of automotive exhaust valves of $\gamma$-TiAl based alloys. The flow fields and the temperature fields during the mould filling and solidification processes are obtained by calculation. Three kinds of potential defects including the gas bubbles and the surface air entrainment occurred in the mould filling and the shrinkage porosities formed in the solidification process are predicted. The influences of filling pressure difference control methods and moulds on gas bubble and surface air entrainment behavior are taken into account in the mould filling simulation. Finally, the evaluation of the mould filling and solidification simulation results are carried out by water analogue and suction casting experiments.

\section{Experimental}

\subsection{Suction casting experiment}

Fig. 1(a) illustrates the schematic view of the investment mould with a graphite riser tube sealed in the suction casting can which is attached to the end of a hollow lifting rod. This is connected by a flexible hose to a vacuum system via control valves and a gas tank $(0 \mathrm{~Pa})$. Having loaded the $7 \mathrm{~kg}$ melting stock of Ti45Al8NbiB (at.\%) alloy into a $25 \mathrm{Kg}$ capacity $\mathrm{CaO}$ crucible, the mould of TiAl automotive valves (Fig. 1(b)) with its thermal insulation devices (Fig. 1(c)), which included an opening stainless steel bin and some silica sand, were mounted in the suction casting can, all of which were preheated to $873 \mathrm{~K}$. After evacuating a melting chamber and a suction casting chamber, they were then filled with argon to a partial pressure of $80000 \mathrm{~Pa}$, which made the filling pressure difference between the melting chamber and the gas tank be equal to $80000 \mathrm{~Pa}$. Once the TiAl molten metal heated by induction coils reached a stable temperature of $1953 \mathrm{~K}$, the suction casting can be moved downwards to dip the riser tube into the molten metal, and a pre-set pressure difference profile between the interior and exterior of the investment mould was built up to suck the molten metal uphill by means of switching the control valves on and regulating the rate of air leakage flow through these valves. The riser tube was held in the molten metal for a long
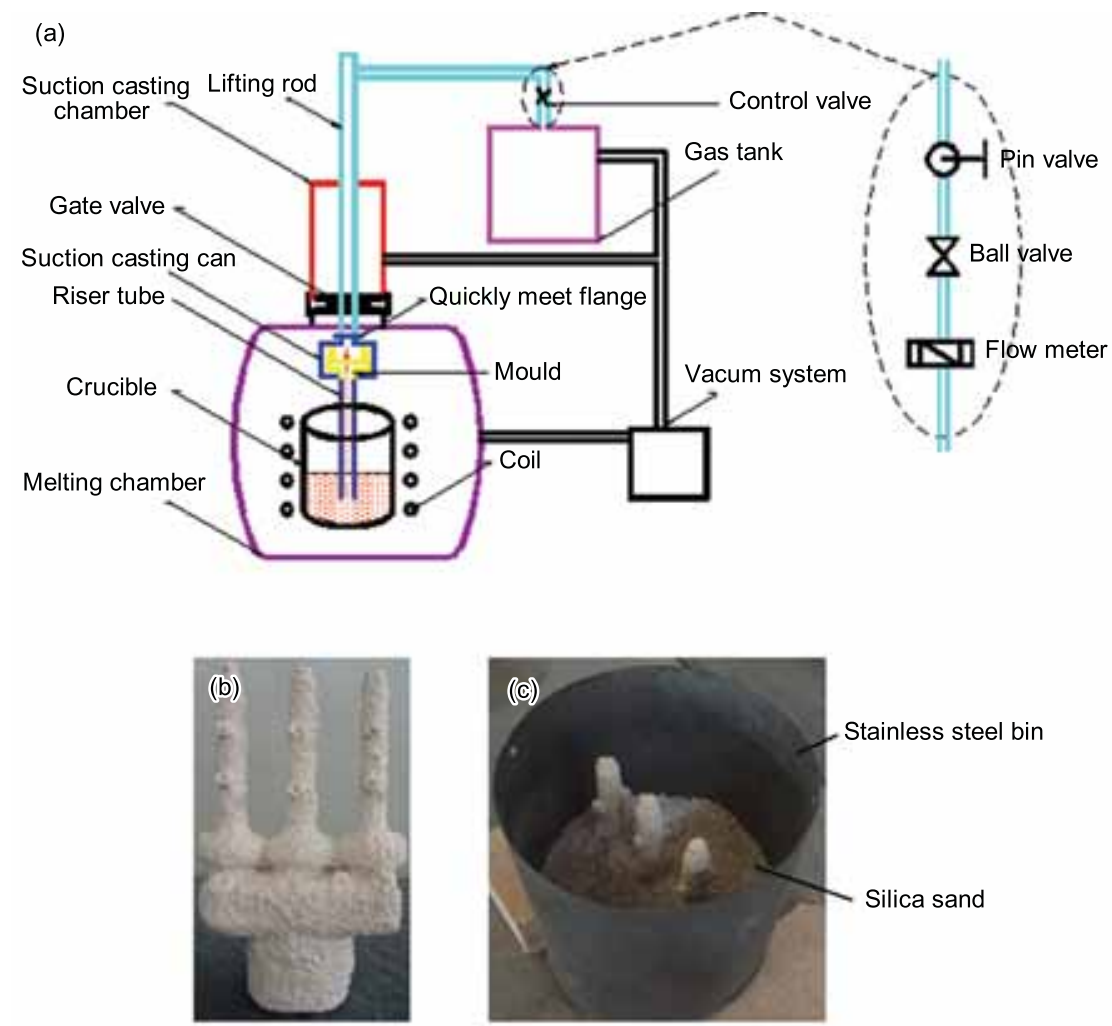

Fig. 1 Suction casting equipments: (a) schematic sketch of suction casting furnace; (b) mould of TiAl automotive valves; (c) thermal insulation devices for mould 
enough time, called pressure hold-up time, so that the mould would be completely filled and the castings solidified soundly; and then it was removed from the molten metal to drain the residual melt in the mould cavity back into the crucible. After casting, the castings of TiAl automotive valves were furnace-cooled. Adhering investment was removed carefully by sandblasting. A sophisticated 3D X-ray inspection system, GE SEIFERT DP435, was used to inspect gas porosities in the castings. The finished castings were cut from the middle vertical section by wire cutting to detect the shrinkage porosities.

\subsection{Numerical simulation}

The commercial, general-purpose computational fluid dynamics (CFD) code FLOW-3D is used here to simulate the mould filling of suction casting of TiAl automotive valves, which solves the coupled mass, momentum, energy equations based on the finite volume/finite difference method (FDM) ${ }^{[17]}$. The volume of fluid (VOF) approach is adopted for the accurate capture of free-surface dynamics. A laminar model and a renormalization-group (RNG) model are employed to depict the laminar and turbulent characteristics in the mould filling, respectively. And the RNG model describes low intensity turbulence flows and flows having strong shear regions, which are a case for concern in this study, more accurately than the frequently-used standard $k-\varepsilon$ model does ${ }^{[18]}$.

As far as the gas bubbles are considered, the VOF method, a simple adiabatic bubble model in conjunction with a valve model are implemented to simulate their dynamic behavior ${ }^{[19]}$. Since the density of the liquid phase is typically three orders of magnitude higher than that of the gas phase, the bubbles may reasonably be treated as void regions filled with ideal gas with uniform pressure and temperature, and the gas motion inside the bubbles is neglected for the sake of simplicity. With resort to a marker variable $F$, the volume fraction of liquid in a computational cell, which takes values in the range between 0 for gas and 1 for liquid, the size and shape of the bubbles can be determined from the values of $F$ in neighboring cells. The governing equation for $F$ is given by

$$
\frac{\partial F}{\partial t}+\nabla(F \vec{U})=0
$$

which is used to advance the bubble-liquid boundaries, where $\vec{U}$ is the liquid velocity vector. Moreover, the progressive deformation of a bubble is assumed isentropic so that the pressure, $P$, inside the bubble may be related to the bubble volume, $V$, by

$$
P V^{\gamma}=\text { const }
$$

where $\gamma$ is the ratio of specific heat capacity at constant pressure to that at constant volume. The pressure of a coalesced bubble is achieved by volume weighting the pressures of the previous isolated bubbles. The valve model in the FLOW-3D software can be used to vent the adiabatic bubbles to the outside of the mould. The valve can be placed at any location in the mould. Assumed that the evacuating flow keeps incompressible and steady, the volumetric flow rate through the valve can be derived by the standard formulation:

$$
Q=A \Upsilon C \sqrt{\frac{\left|P-P_{\mathrm{ref}}\right|}{\rho}}
$$

where $Q$ is the volumetric flow rate; $A$ is the cross sectional area of the vent; $\Upsilon, C$ and $\rho$ are the compressible factor, the frictional loss coefficient and the density for the bubble gas, respectively; $P_{\text {ref }}$ is the external reference pressure.

The air entrainment is another defect which is undesirable in the runner systems used by metal casters. The air entrainment at a liquid surface is derived from the idea that turbulent eddies lift up the small liquid elements above a free surface that may seize air and bring it back into the liquid ${ }^{[20]}$. The basic entrainment process is based on a competition between the stabilizing forces of gravity and surface tension and the destabilizing effect of surface turbulence. In terms of the turbulence transport models, the characteristic size, $L$, of the turbulent eddies is deduced by

$$
L=0.1 \frac{\sqrt{k^{3}}}{\varepsilon}
$$

where $k$ is the turbulent kinetic energy, $\varepsilon$ is the turbulent dissipation function. We use this scale to characterize surface stabilizing energy. The stabilizing kinetic energy per unit volume, $E_{\text {stab }}$, associated with the liquid element raised to a height $L$, and with the surface tension energy based on a curvature of $L$, is calculated by

$$
E_{\text {stab }}=\rho_{1} g L+\frac{\sigma}{L}
$$

where $\rho_{\mathrm{l}}$ is the liquid density, $g$ is the component of gravity normal to the free surface, $\sigma$ is the surface tension coefficient. As the air entrainment occur, turbulent kinetic energy per unit volume, $E_{\text {turb }}=\rho_{\mathrm{l}} k$, must be larger than $E_{\text {stab. }}$. The volume of air entrained per unit time, $\delta V$, should be proportional to the surface area, $A_{\mathrm{s}}$, and the height of the disturbances above the mean surface level which can be formulated to:

$$
\delta V=C_{\text {air }} A_{\mathrm{s}} \sqrt{\frac{2\left(E_{\text {turb }}-E_{\text {stab }}\right)}{\rho_{\mathrm{l}}}}
$$

where $C_{\text {air }}$ is the coefficient of proportionality $\left(C_{\text {air }}\right.$ is equal to 0.5$)$.

The solidification process of suction casting of TiAl automotive valves is studied using the ProCAST package, which is based on the finite element method (FEM), to solve the coupling among the mass, momentum and energy conservation equations. According to the suction casting process, the appropriate pressure hold-up time, which is defined as trading off 
casting intergrity and the weight of the molten metal drained back into the crucible, must be determined at first in order to predict the formation of the shrinkage porosities. By means of a unique draining algorithm, all the remaining liquid in the mould cavity, which is down to the solid fraction defined by DRAINFS (DRAINFS takes value of 0.7 in this study) and is connected to the inlet region of the riser tube, will be removed at the time specified by the value of DRAINTIME, so the appropriate pressure hold-up time can be determined. The shrinkage porosities which forms during the solidification process of TiAl automotive valves include macroporosities and microporosities, and they are modeled using the ISOCHRONS function and the Niyama criteria function, respectively ${ }^{[15]}$.

Fig. 2(a) shows the complete geometry for the mould filling simulation of $\mathrm{TiAl}$ automotive valves. To improve the simulation accuracy the crucible was involved as can rarely be seen in some previous publications ${ }^{[12,16,21]}$. On account of a short filling time, the effect of the opening stainless steel bin and the silica sand on the mould filling simulation was negligible. The volume of a gas channel is equal to that of the connecting duct between the suction casting can and the control valves (Fig. 1(a)) in the suction casting furnace. The mesh setup of the geometry is given in Fig. 2(b). The geometry was subdivided into brick-type orthogonal elements, in a zig-zag fashion to approach the real casting contour. The total number of the elements was 2406400 , with an average element size of $0.0025 \mathrm{~m}$.

After meshing, the other simulation set-up was done, which included applying to the various regions initial conditions, boundary conditions and material definitions. The initial and boundary conditions for the mould filling simulation can be outlined as illustrated in Fig. 2(c). The details of the initial conditions needed for the mould filling simulation are listed in Table 1. Initially the molten metal in the crucible was stagnated. The no-slip condition and the freeslip condition were the boundary conditions for the flow fields at the interior walls of the gating system components, consisted of the graphite riser tube and the investment mould, and at the free surface of the molten metal, respectively. The valve model mentioned before was mounted on the center of the upper surface of the gas channel to release the bubble gas to the outside of the mould. According to Eq. (3), two important parameters must be defined in order to calculate the volumetric flow rate through the valve, $Q$, one is the external reference pressure, $P_{\text {ref }}$, which was $0 \mathrm{~Pa}$; the other is the valve loss coefficient, $C_{\mathrm{val}}$, which take the form of

$$
C_{\mathrm{val}}=\frac{A \Upsilon C}{\sqrt{\rho}}
$$

Two situations can be met when the $C_{\text {val }}$ was determined: the first was that, in general suction casting $^{[22]}$, a full-open ball valve with a nominal diameter of $0.0008 \mathrm{~m}$ was account for venting adiabatic bubbles to the outside of the investment mould, so the cross sectional area of the vent, $A$, was a known quantity, the $C_{v a l}$ can be calculated by equation (7) directly ( $\Upsilon$ and $C$ both took value of 1 ); the second was that, in "air leakage" suction casting ${ }^{[22]}$, a pin valve, a ball valve and a flow meter were used to manipulate the air leakage flow rate, hence the volumetric flow rate, $Q$, was a known quantity and not
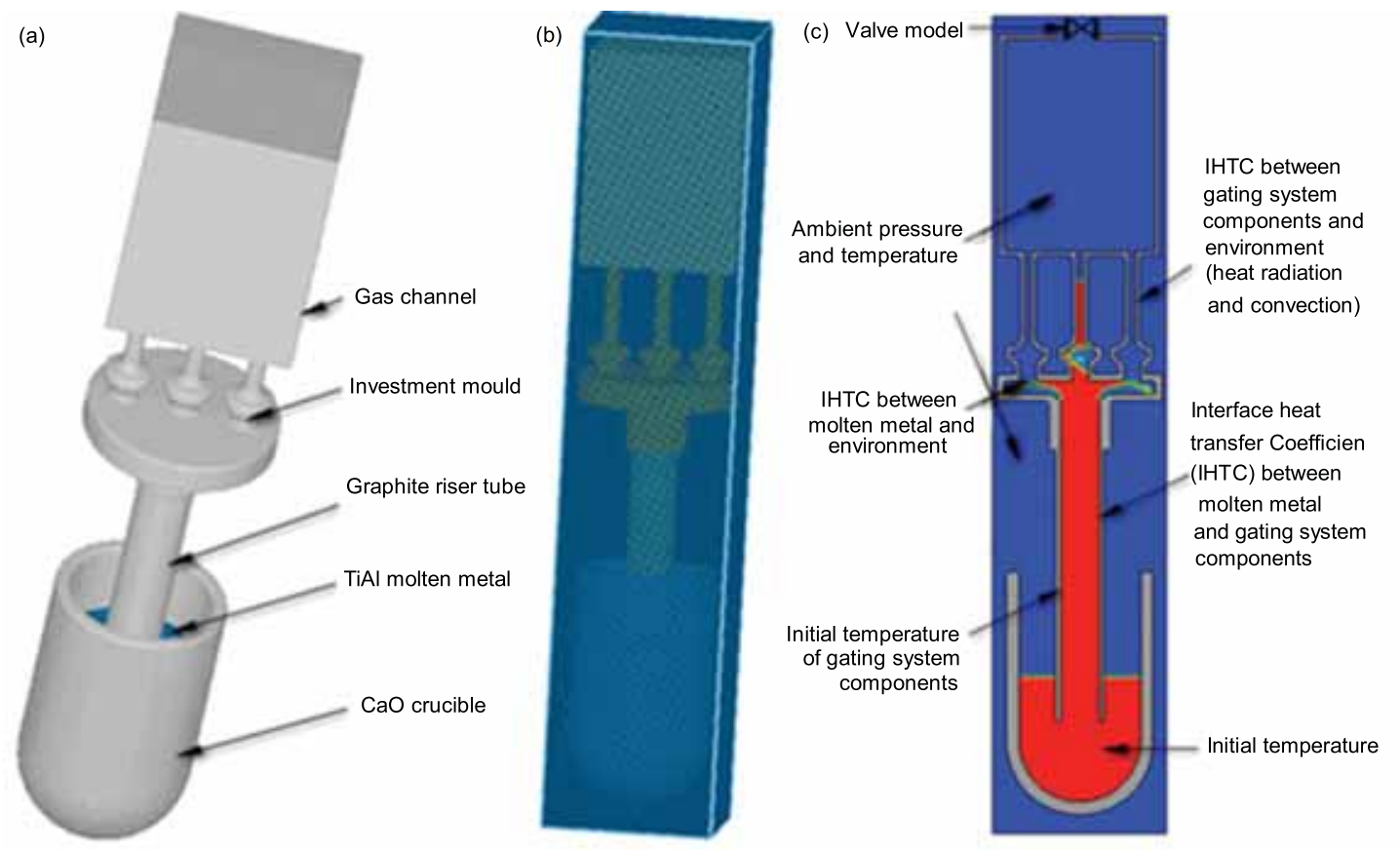

Fig. 2 Geometry (a), FDM meshes (b) and initial and boundary conditions (c) for mould filling simulation of TiAl automotive valves 
was the $A$, the $C_{\text {val }}$ can de deduced from Eq. (3) and (7):

$$
C_{\mathrm{val}}=\frac{Q}{\sqrt{\left|P-P_{\mathrm{ref}}\right|}}
$$

Taking account of the heat exchange into consideration during the mould filling process, the interface heat transfer coefficients among the TiAl molten metal, the gating system components and the surrounding environment should be set. Due to the suction casting reality, the $\mathrm{CaO}$ crucible and the gas channel were taken as adiabatic bodies. Contact heat conduction dominated at the interface between the molten metal and the gating system components. The heat flux, $q$, through this interface was calculated according to

$$
q=h\left(T_{1}-T_{2}\right)
$$

where $h$ is the convection heat transfer coefficient, $T_{1}$ is the temperature of the molten metal surface and $T_{2}$ is the interior wall temperature of the gating system components. The heat transfer from the free surface of the molten metal and the exterior walls of the gating system components to their surrounding environment occurred by the combination of natural convection and radiation. A heat transfer coefficient for the natural convection and a radiation boundary condition were applied to the surfaces with the heat flux, $q^{\prime}$, given by

$$
q^{\prime}=h^{\prime}\left(T_{3}-T_{4}\right)+\delta \xi\left(T_{3}^{4}-T_{4}^{4}\right)
$$

where $h^{\prime}$ is the convection heat transfer coefficient (approximately $10 \mathrm{Wm}^{-2} \mathrm{~K}^{-1}$ ), $T_{3}$ is the temperature of the free surface of the molten metal or the exterior walls of the gating system components, $T_{4}$ is the ambient temperature, $\delta$ is the Stefan-Boltzmann constant $\left(5.67 \times 10^{-8} \mathrm{Wm}^{-2} \mathrm{~K}^{-4}\right), \xi$ is the heat emissivity of the molten metal or the gating system components. The interface heat transfer coefficients between the gating system components employed the FLOW$3 \mathrm{D}$ default values. Table 2 summarizes the details of the convection heat transfer coefficients and the heat emissivities need for the simulation from reviewing the current literature ${ }^{[23-30]}$.

A sequentially coupled mathematical thermal model, based on the commercial code ProCAST, was developed to simulate the solidification process of TiAl automotive valves. The profile of the pressure difference between the interior and exterior of the mould cavity obtained from the mould filling simulation was employed as an inlet pressure boundary condition input to the solidification simulation. Owing to this reason, the $\mathrm{CaO}$ crucible was excluded from the geometry for the solidification simulation which encompassed the graphite riser tube, the investment mould, and the opening stainless steel bin filled with the silica sand, as was obvious from Fig. 3(a). The geometry was automatically meshed using irregular triangle elements, of which the minimum length across the inlet region of the riser tube and the valves domain was $0.001 \mathrm{~m}$ (Fig. 3(b)). The final mesh consisted of 1348765 elements and 283180 nodes. Fig. 3(c) presents the initial and boundary conditions for the solidification process simulation. The details of the initial conditions needed for the solidification process

Table 1 Initial conditions applied to suction casting simulation of TiAl automotive valves

\begin{tabular}{|c|c|c|c|c|c|c|c|c|}
\hline \multirow[t]{2}{*}{ Temperature /K } & \multicolumn{2}{|c|}{$\begin{array}{l}\text { Convection heat transfer } \\
\text { coefficient } /\left(\mathrm{Wm}^{-2} \mathrm{~K}^{-1}\right)\end{array}$} & \multirow[t]{2}{*}{ Temperature /K } & \multicolumn{5}{|c|}{ Emissivity } \\
\hline & $\begin{array}{c}\text { Between TiAl } \\
\text { molten metal and } \\
\text { graphite riser tube }\end{array}$ & $\begin{array}{c}\text { Between TiAl } \\
\text { molten metal and } \\
\text { investment mould }\end{array}$ & & $\begin{array}{c}\text { Graphite } \\
\text { riser } \\
\text { tube }\end{array}$ & $\begin{array}{l}\text { TiAl } \\
\text { molten } \\
\text { metal }\end{array}$ & $\begin{array}{l}\text { Investment } \\
\text { mould }\end{array}$ & $\begin{array}{l}\text { Silica } \\
\text { sand } \\
\text { bin }\end{array}$ & $\begin{array}{l}\text { Stainless } \\
\text { steel }\end{array}$ \\
\hline 773 & 115 & 115 & 1545 & 0.53 & & & & \\
\hline 1273 & 265 & 265 & 1652 & 0.56 & & & & \\
\hline 1473 & 325 & 325 & 1732 & 0.58 & & & & \\
\hline 1773 & 1500 & 1000 & 1832 & 0.6 & 0.324 & 0.615 & 0.6 & 0.7 \\
\hline 1853 & 2000 & 1500 & 1940 & 0.62 & & & & \\
\hline 1953 & 2000 & 1500 & 2040 & 0.63 & & & & \\
\hline- & - & - & 2140 & 0.63 & & & & \\
\hline- & - & - & 2240 & 0.64 & & & & \\
\hline
\end{tabular}

\begin{tabular}{cccccccc}
\hline & \multicolumn{3}{c}{ Temperature $/ \mathrm{K}$} & & Ambient & Reference \\
piAl & Graphite & Investment & Stainless & Silica \\
molten metal & riser tube & mould & Ambient & pressure $/$ Pa & sand & & \\
\hline 1953 & 323 & 654 & 654 & 654 & 298 & 80000 & 0 \\
\hline
\end{tabular}

Table 2 Interface heat transfer coefficients utilized for suction casting modeling of TiAl automotive valves 

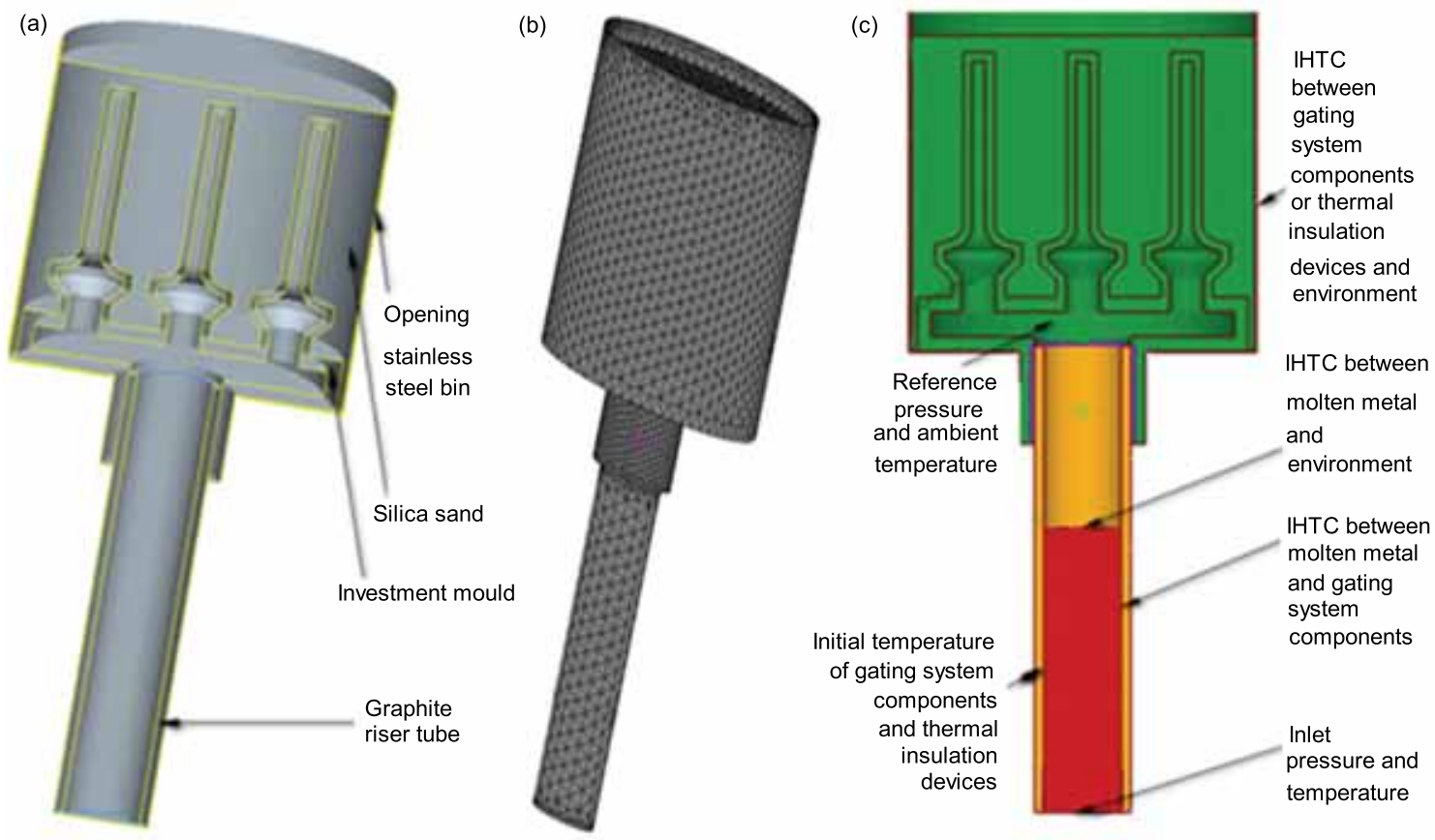

Fig. 3 Geometry (a), FEM meshes (b) and initial and boundary conditions (c) for solidification process simulation of $\mathrm{TiAl}$ automotive valves

simulation are also given in Table 1 . The boundary conditions for the velocity fields at the interior walls of the gating system components and at the free surface of the molten metal were in accordance with those of the mould filling simulation. As discussed above, the inlet pressure derived from the results of the mould filling modeling, and the inlet temperature of the TiAl molten metal was fixed to $1953 \mathrm{~K}$. Besides the heat exchange among the TiAl molten metal, the gating system components and the surrounding environment which had been referred to in the mould filling simulation, the heat transfer between the thermal insulation devices and the surrounding environment should be taken into account. The natural convection and radiation were both responsible for the heat transfer from the exterior walls of the thermal insulation devices to their surrounding environment. The heat flux during this process can also be characterized by Eq. (10). The necessary heat emissivities of the stainless steel bin and the silica sand have been listed in Table 2.

Since the behavior of the materials employed in the suction casting process of TiAl automotive valves was modeled over a wide range of temperature, the temperature dependencies of the properties of these materials must be included to the extent possible with available data. The thermophysical data needed for the TiAl molten metal ${ }^{[31-34]}$, the graphite riser tube $^{[35]}$ and the investment mould ${ }^{[25,36]}$ compiled from various sources and had been summarized in Fig. 4-Fig. 6, and the temperature dependent thermophysical properties of the silica sand and the stainless steel bin were chosen from the ProCAST database. The solidus and liquidus of the TiAl molten metal were found to be 1773 and $1853 \mathrm{~K}^{[34]}$, respectively. The phase transition problem during the solidification process of the TiAl molten metal was accounted for using the enthalpy method in the solidification process simulation, but in the mould filling modeling, a latent heat of $411500 \mathrm{~J} \cdot \mathrm{kg}^{-1}[32,37]$ was assumed to be released linearly between the solidus and liquidus temperatures.

\subsection{Water analogue experiment}

A water model was established to allow the direct observation of the filling patterns during the suction casting process of automotive valves. Coloured water was used as the working fluid and the experimental mould of which the geometry size was identical with that of the investment mould in the real suction casting was made from transparent acrylic. The flow patterns of water and the gas bubble behavior in the mould were recorded by a digital camera, and the digital video images were captured at a rate of 25 frames per second using the video capture software Adobe Premiere. The experimental set-up and procedures had been dealt with elaborately in a previous publication ${ }^{[22]}$ and, consequently, were not reproduced here.

\section{Results and Discussion}

\subsection{Gas bubbles and surface air entrainment}

Two types of filling pressure difference control methods and moulds were involved in the mould filling simulation. The dimensions of the cylindrical runner 

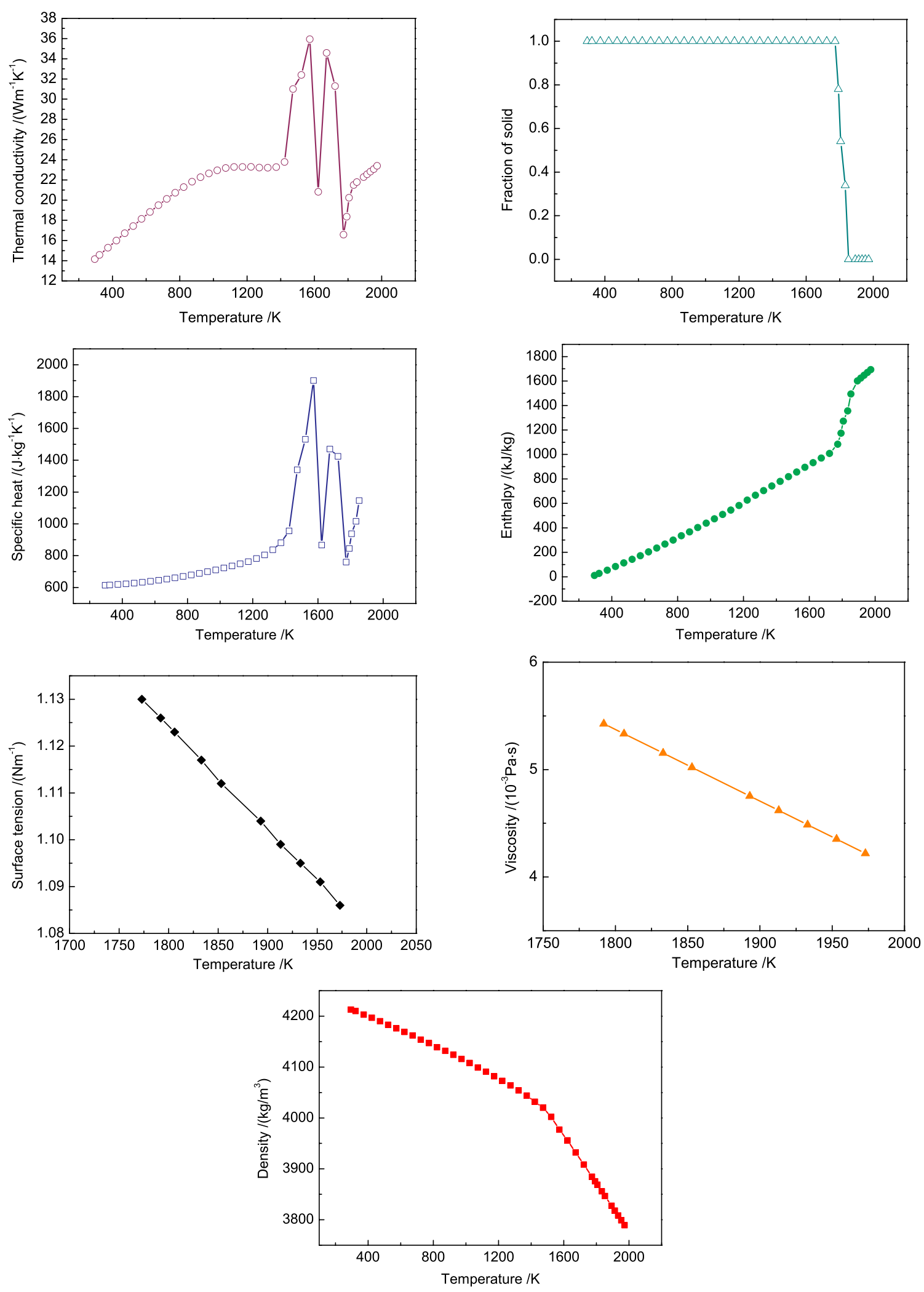

Fig. 4 Thermophysical properties of the TiAl molten metal

and the tetragonal runner in the two types of moulds were $\Phi 0.175 \mathrm{~m} \times 0.015 \mathrm{~m}$ and $0.116 \mathrm{~m} \times 0.064 \mathrm{~m} \times$ $0.020 \mathrm{~m}$, respectively, but otherwise were identical as seen in Fig. 7. The two types of filling pressure difference control methods, the general and "air leakage" suction casting, had been discussed in section 2.2.
The details of variable parameters are listed in Table 3 and other cast parameters keep invariant which have been also given in section 2.2 .

The predicted mould filling sequences and the calculated pressure changes in the mould cavity of six projects are shown in Fig. 8-Fig. 10. For the general 

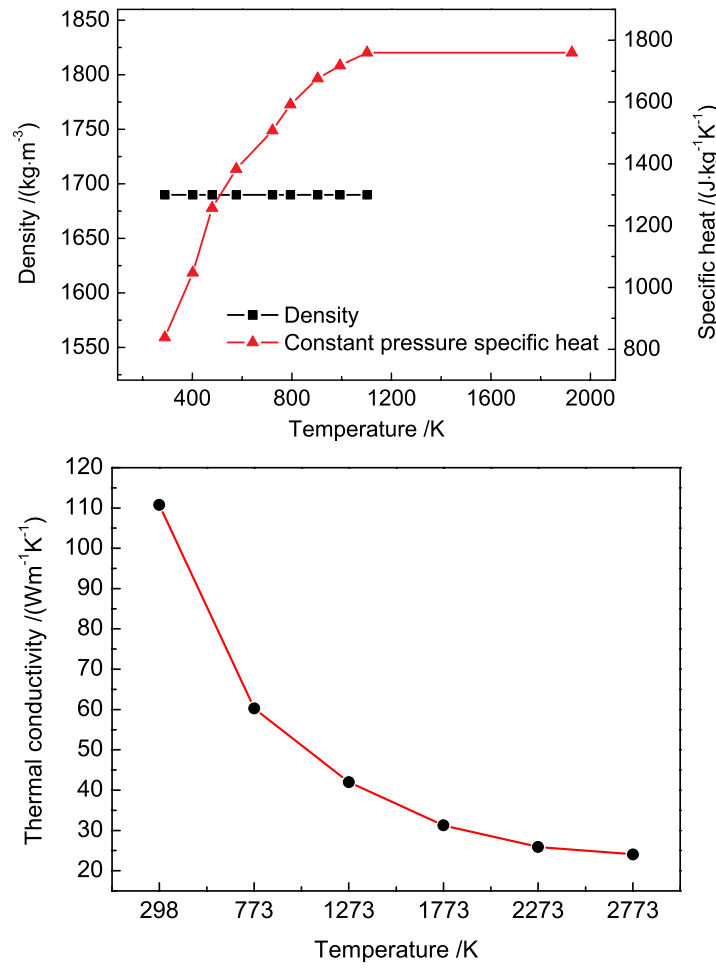

Fig. 5 Thermophysical properties of the graphite riser tube
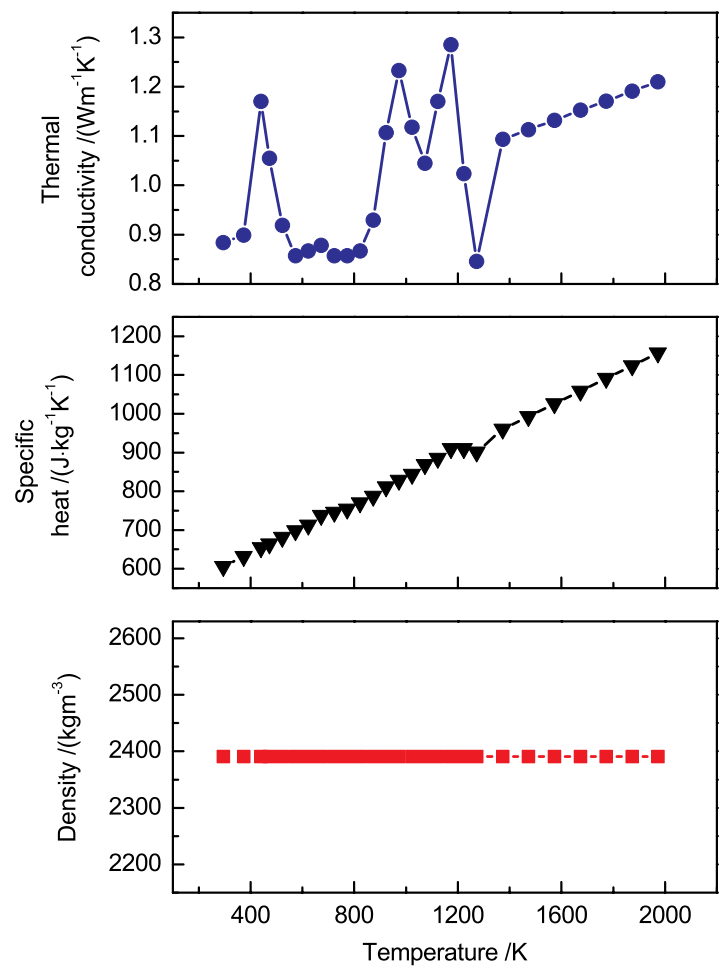

Fig. 6 Thermophysical properties of the investment mould

suction casting with the full-open ball valve of the $0.008 \mathrm{~m}$ nominal diameter regulating the filling pressure difference change, the pressure in the mould cavity fell sharply (Fig. 10) so that the filling pressure difference jumped steeply. Due to the filling pressure difference action, the TiAl molten metal filled the

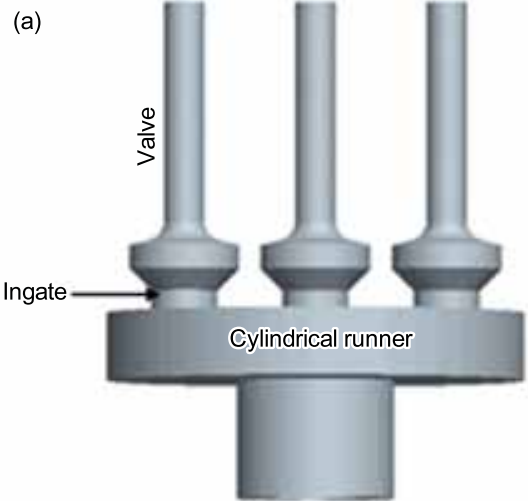

(b)

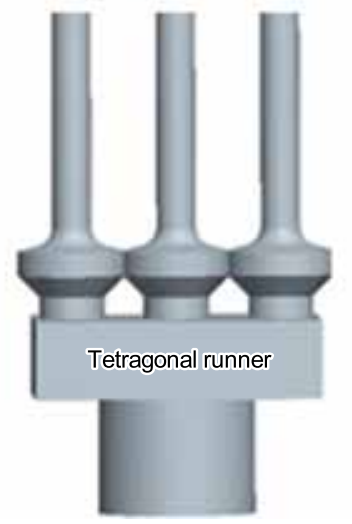

Fig. 7 Mould geometry used in mould filling simulation of TiAl automotive valves: (a) mould with cylindrical runner; (b) mould with tetragonal runner

mould very fast and the free surface of the molten metal exhibited convex curvature (Fig. 8(a)). The molten metal advance front reached the center valve of the mould firstly, and then reached the bilateral valves (Fig. 8(b)). At the moment when the molten metal front struke the ceiling of the cylindrical runner acutely, the molten metal splashed about and a large number of gas bubbles (denoted by yellow circles) emerged. The gas bubbles rose to the valve parts as the filling proceeded (Fig. 8(a)-(c)). For the sake of a relatively high filling speed, the surface turbulence of the molten metal was in a high-level and the volumetric fraction of the entrained air occurred during mould filling was large (Fig. 8(a)-(c)), e.g., the volumetric fraction of the entrained air at a time of $0.30 \mathrm{~s}$ was equal to $35.4 \%$. For the "air leakage" suction casting with an air leakage flow rate of $8.44 \times$ $10^{-4} \mathrm{~m}^{3} \mathrm{~s}^{-1}$, the filling pressure difference increased gradually (Fig. 10), so the mould filling velocity was lower than that of the general suction casting. Sequential filling was achieved, i.e., the molten metal filled the cylindrical runner tranquilly and the molten metal front arrived in all three valves of the mould at the same time (Fig. 8(d) and (e)). But according to the mass conservation law of fluid mechanics, the filling velocity of the valve parts was higher than those of the riser tube and the cylindrical runner. That is the reason why a small amount of gas bubbles appeared in this region (Fig. 8(e) and (f)). By comparing Fig. $8(\mathrm{~b})$ and (e), it is evident that the volumetric fraction 
Chao XIONG et al.: Acta Metall. Sin. (Engl. Lett.), 2013, 26(1), 33-48.

Table 3 Variable parameters employed in mould filling simulation of TiAl automotive valves

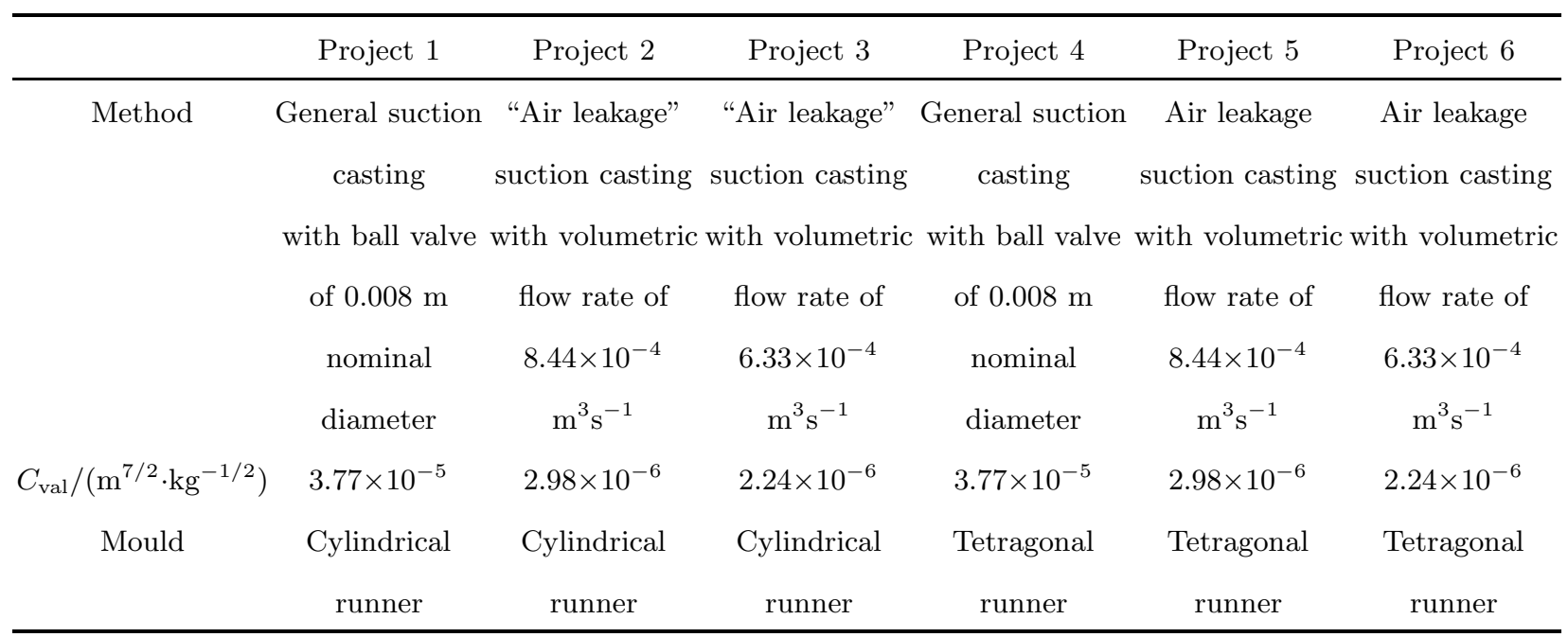
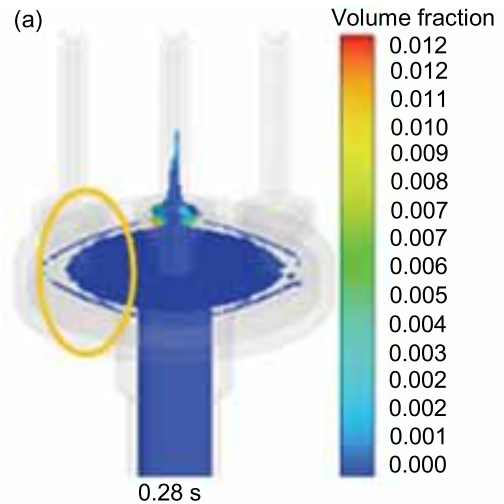

(d) Volume fraction

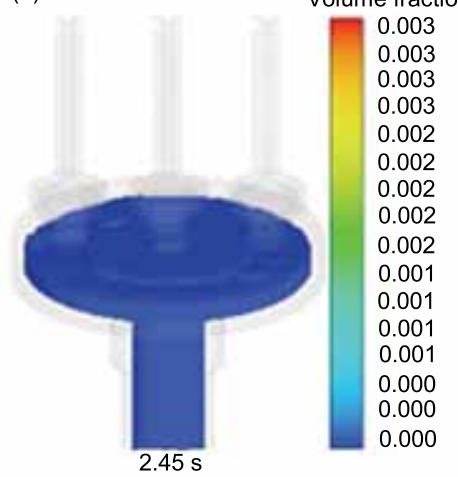

(g)

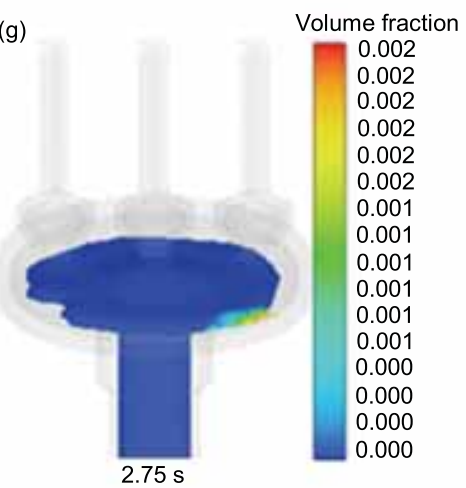

(b)

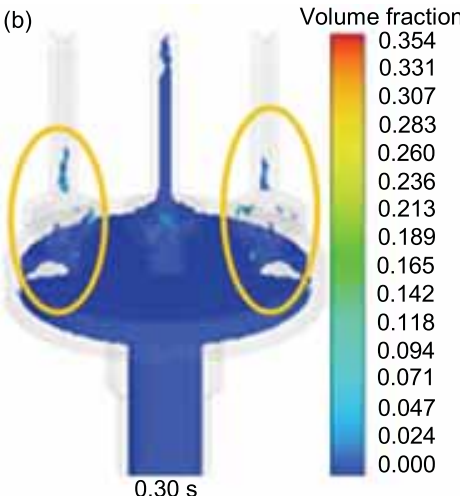

(e)

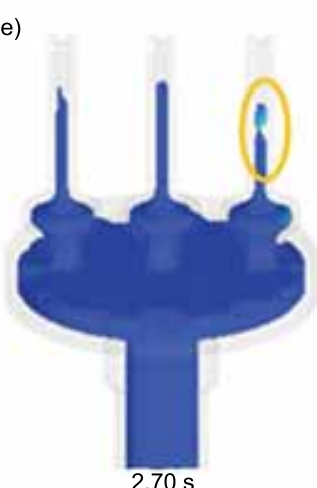

(h)

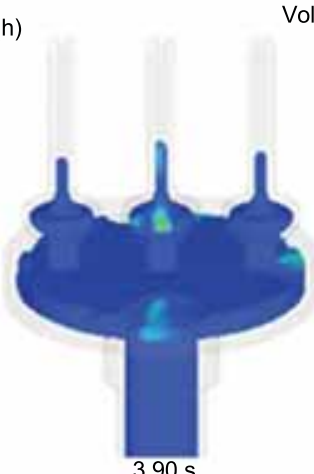

Volume fraction (f)

(c) Volume fraction
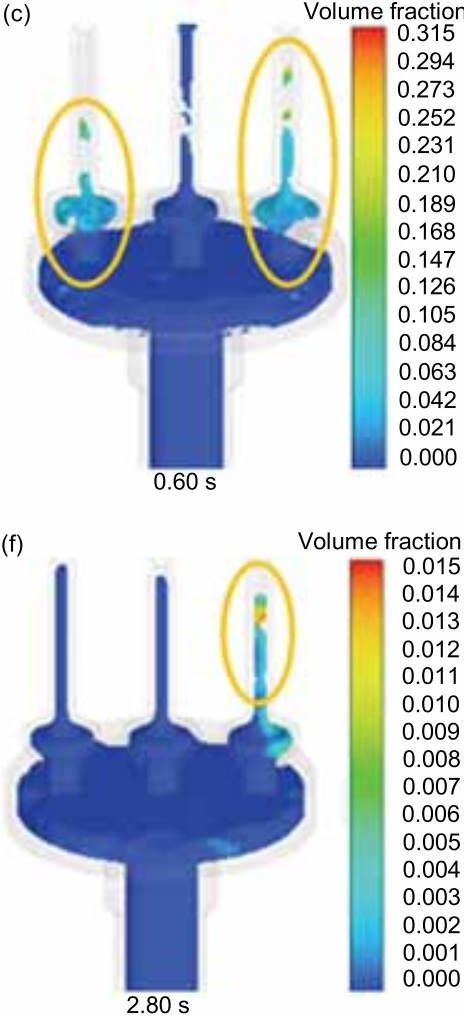

(i)
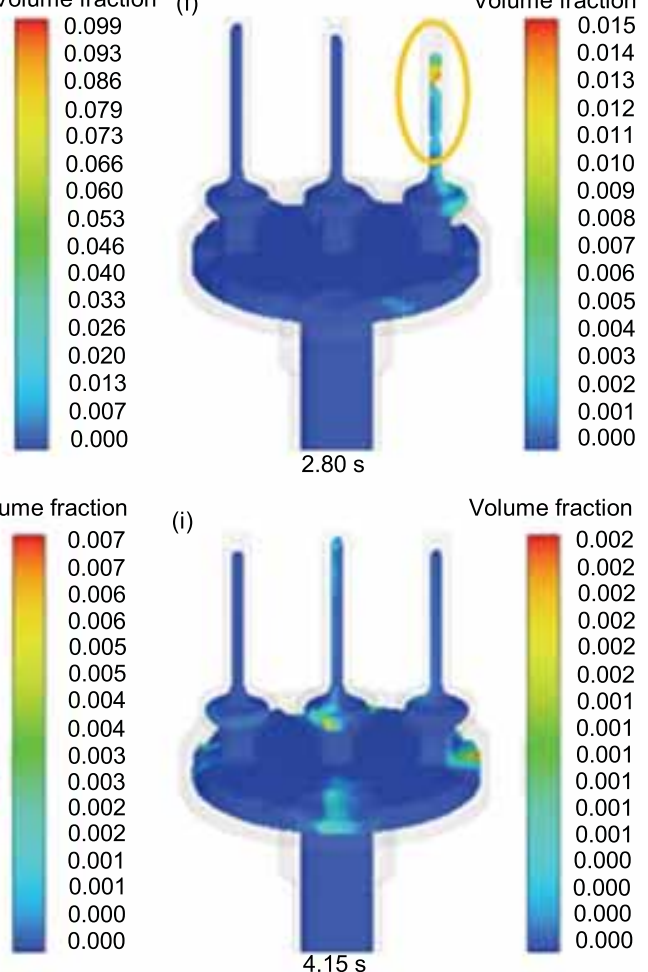

Fig. 8 Mould filling sequence observed in suction casting simulation of TiAl automotive valves at different times: $(\mathrm{a}-\mathrm{c})$ project $1 ;(\mathrm{d}-\mathrm{f})$ project $2 ;(\mathrm{g}-\mathrm{i})$ project 3 (colored by volumetric fraction of entrained air) 
(a)

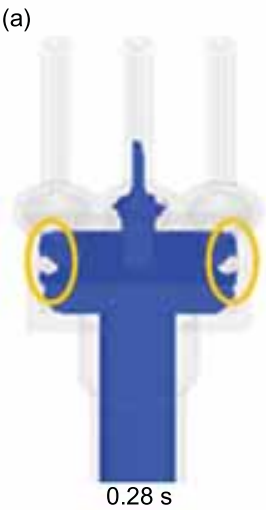

(d)

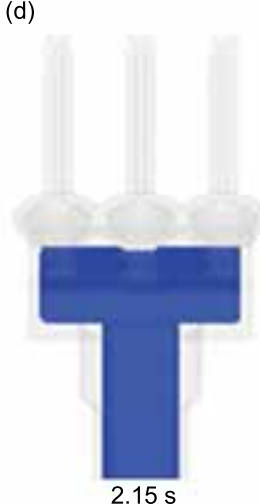

(g)

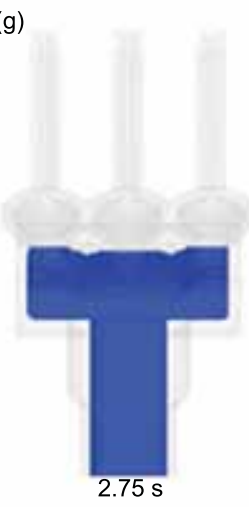

Volume fraction
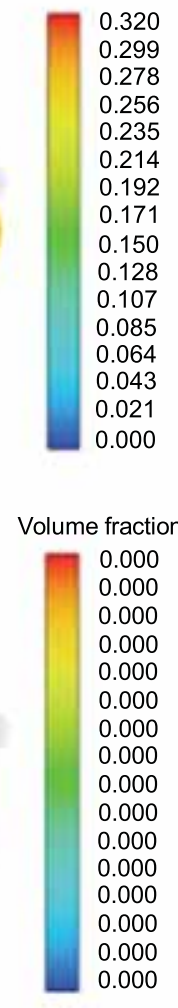

Volume fraction

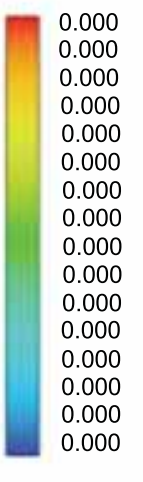

(b)
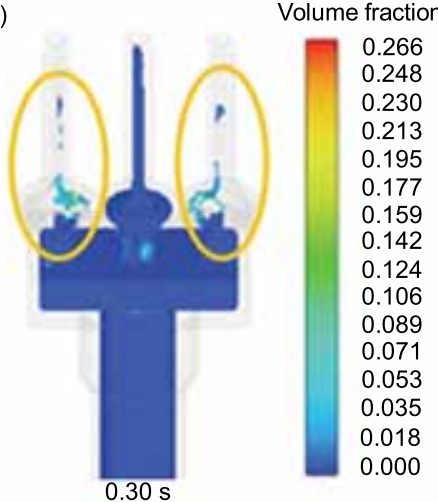

(e)

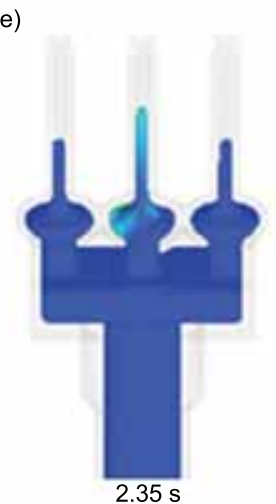

(h)

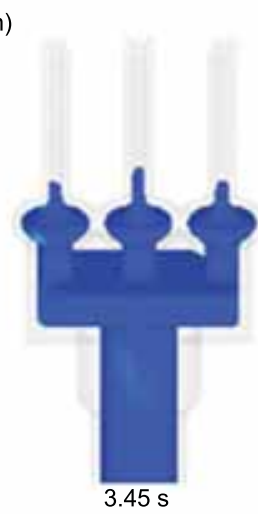

Volume fraction

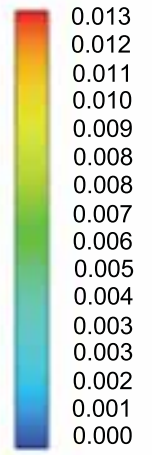

Volume fraction

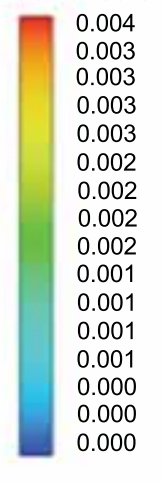

(c)

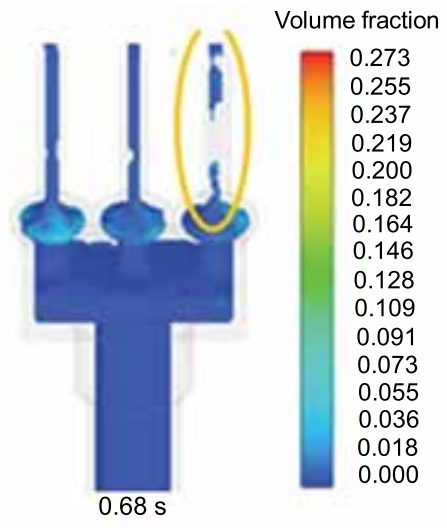

(f)

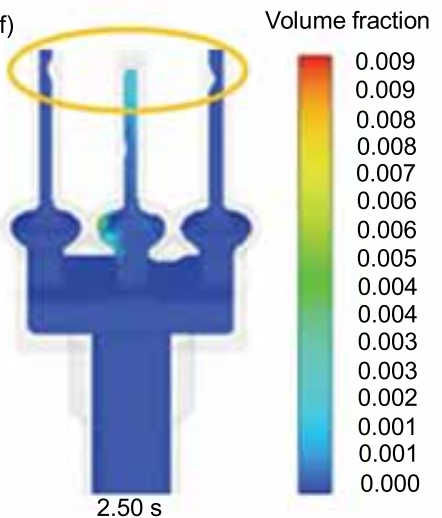

(i)

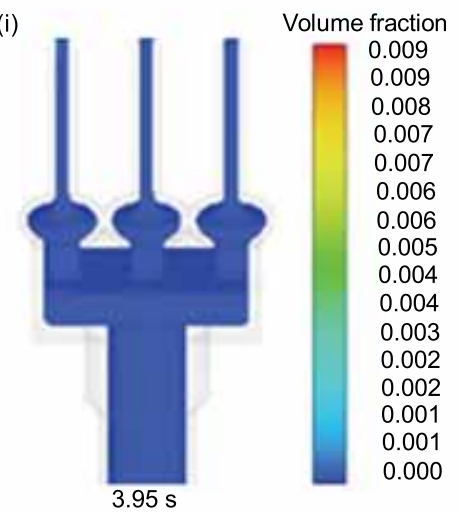

Fig. 9 Mould filling sequence observed in suction casting simulation of TiAl automotive valves at different times: $(\mathrm{a}-\mathrm{c})$ project $4 ;(\mathrm{d}-\mathrm{f})$ project $5 ;(\mathrm{g}-\mathrm{i})$ project 6 (colored by volumetric fraction of entrained air)

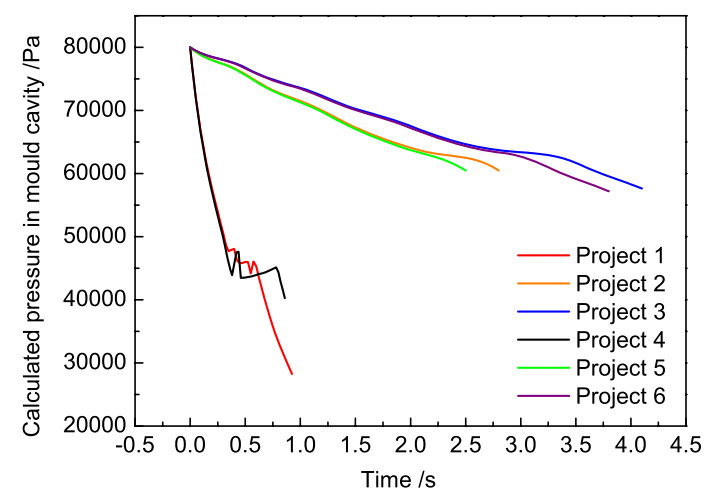

Fig. 10 Calculated pressure changes in mould cavity of the entrained air reduced dramatically, which can also be attributed to the low filling velocity.
As we reduced the air leakage flow rate to $6.33 \times$ $10^{-4} \mathrm{~m}^{3} \mathrm{~s}^{-1}$, the filling pressure difference increased slightly (Fig. 10). The filling velocity was the lowest among the three projects. As shown in Fig. 8(g)-(i), the sequential and complete filling without the gas bubbles were achieved, and the volumetric fraction of the entrained air decreased to the smallest value.

As for another type of mould, the mould with the tetragonal runner, the effect of this mould on filling patterns and the gas bubble behavior is negligible by comparing the mould filling simulation results using the mould with the tetragonal runner (Fig. 9) to those using the mould with the cylindrical runner (Fig. 8). Matching of the pressure curves among projects 1 and 4 , projects 2 and 5 as well as projects 3 and 6 is taken to be the sufficient indication of this effect (Fig. 10). 
In term of the surface air entrainment, careful examinations of Fig. 8(a)-(c) and Fig. 9(a)-(c), Fig. 8(d)-(f) and Fig. 9(d)-(f) as well as Fig. 8(g)-(i) and Fig. 9(d)-(f) suggested that the volumetric fraction of the entrained air was somewhat lower when the mould with the tetragonal runner was employed than that when the mould with the cylindrical runner was utilized. Since the cross-sectional area ratio of the three parts, the riser tube, the runner and the ingate, of the mould with the tetragonal runner which was assumed to be 1.7:6.2:1 was much smaller than that of the mould with the cylindrical runner which took value of $1.7: 25.5: 1$, the filling velocity of the mould with the tetragonal runner changed more gently than that of the mould with the cylindrical runner according to the mass conservation law of fluid mechanics, and the turbulent energy occurred during the filling of the mould with the tetragonal runner became lower than that happened during the filling of the mould with the cylindrical runner, which can be seen in Fig. 11. That is a possible explanation for the effect of the mould with the tetragonal runner on the surface air entrainment.

Summarizing the discussion above, the "air leakage" suction casting with an air leakage flow rate of $6.33 \times 10^{-4} \mathrm{~m}^{3} \mathrm{~s}^{-1}$ and the mould with the tetragonal runner is recommended when intend to cast soundness TiAl automotive valves.

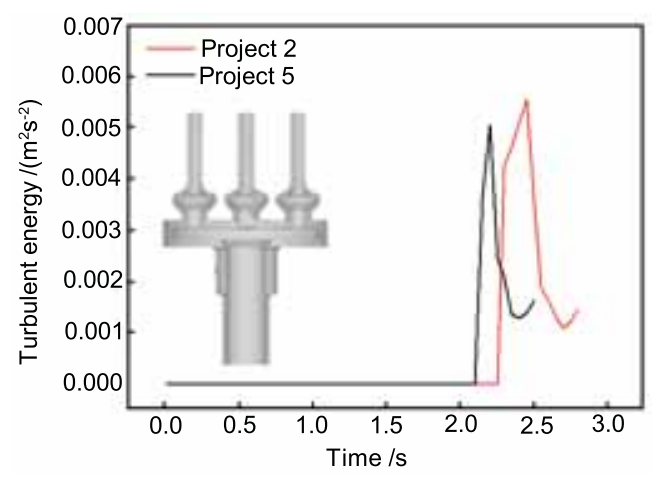

Fig. 11 Turbulent energy of center point of ingate inlet region changes in project 2 and project 5

\subsection{Validation of water analogue and suction casting experiments}

In order to evaluate the accuracy of the mould filling simulation, we compared them to the suction casting and water analogue experiments described in sections 2.1 and 2.3. The mould filling simulation of the water analogue experiments for the general and "air leakage" suction casting were taken into account. The filling processes were assumed to be isothermal and the fluid properties (the density and viscosity at $293 \mathrm{~K}$ ) used were those of water. Two full size geometries were established to simulate the mould filling process of the water analogue experiments, as seen in Fig. 12(a) and (c). The geometries were divided into 1897660 elements (Fig. 12(b)) and 2606912 elements (Fig. 12(d)) with an average element size of $0.003 \mathrm{~m}$. The ambient pressures of the interior and exterior of the mould cavity were $101325 \mathrm{~Pa}$. As discussed in section 2.2, three valve models of which each set at the top of each valve stem of the mould were used to mimic three vents with a $0.008 \mathrm{~m}$ diameter which vented the adiabatic bubbles to the outside of the perspex mould in the water analogue experiment for the general suction casting. All of the external reference pressure, $P_{\text {ref }}$, involved in the three valve models were $89925 \mathrm{~Pa}$, so the filling pressure difference was $11400 \mathrm{~Pa}$. And another important parameter related, the valve loss coefficient, $C_{\text {val }}$, took value of $5 \times$ $10^{-5} \mathrm{~m}^{7 / 2} \cdot \mathrm{kg}^{-1 / 2}$ according to Eq. (7) (the density of air at $295 \mathrm{~K}$ is $1.25 \mathrm{~kg} / \mathrm{m}^{3}$ ). Similar to above, in the mould filling simulation of the water analogue experiment for the "air leakage" suction casting, the only one valve model was arranged on the center of the upper surface of the gas channel to represent the control valves which regulated the air leakage flow rates. The external reference pressure, $P_{\text {ref }}$, was fixed to $50662.5 \mathrm{~Pa}$, and as we knew, the volumetric flow rate through the valve, $Q$, was equal to $1.94 \times 10^{-4} \mathrm{~m}^{3} \mathrm{~s}^{-1}$, the valve loss coefficient, $C_{v a l}$, was deduced to be $8.63 \times$ $10^{-7} \mathrm{~m}^{7 / 2} \cdot \mathrm{kg}^{-1 / 2}$ from Eq. (8) (the ambient pressures of the interior and exterior of the mould cavity
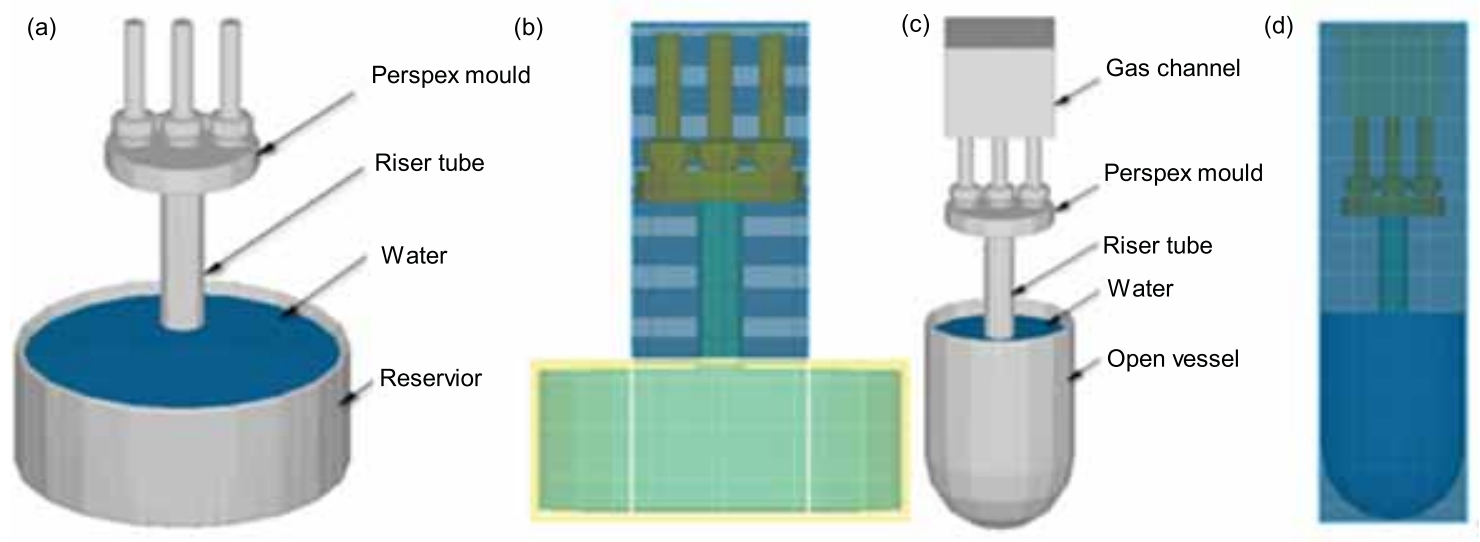

Fig. 12 Modeling set-up for mould filling simulation of water analogue experiment: geometry (a) and FDM meshes (b) for water analogue experiment of general suction casting; geometry (c) and FDM meshes (d) for water analogue experiment of air leakage suction casting 
were $101325 \mathrm{~Pa}$, and the filling pressure difference was $50662.5 \mathrm{~Pa}$.). Fig. 13 presents the comparison of the mould filling sequences between the water analogue experiment of the general suction casting and its numerical simulation. As shown in Fig. 13, the water advance front reached the center valve of the mould firstly, and then reached the bilateral valves resulting from a relatively high filling speed (Fig. 13(b) and (e)). The gas bubbles, denoted by yellow circles, turned up in the cylindrical platform of the perspex mould, but did not appear during filling of the riser tube (Fig. 13(a) and (d)). As the filling continued, they ascended into the valve parts owing to fluid flow action (Fig. 13(b) and (e)). The predicted filling time was $0.28 \mathrm{~s}$, which was identical with that of the water analogue experiment (Fig. 13(c) and (f)). By comparing both of the mould filling phenomena, it can be seen that simulated results agree well with the observed ones in terms of the filling patterns, the gas bubble behavior and the filling time. The same trends previously described continue in the comparison of the predicted and experimental mould filling phenomena in the water analogue test for the "air leakage" suction casting (Fig. 14).
Fig. 15 shows the $\mathrm{X}$-ray radiography and the middle vertical section inspections of TiAl automotive valves manufactured by the general and "air leakage" suction casting. All of the three valves, cast by the general suction casting employing the full-open ball valve of the $0.008 \mathrm{~m}$ nominal diameter to control the filling pressure difference change, had severe gas porosities (Fig. 15(a)). As for the valves fabricated by the "air leakage" suction casting with an air leakage flow rate of $2.78 \times 10^{-3} \mathrm{~m}^{3} \mathrm{~s}^{-1}$, the gas porosities only occurred in two of the three valves (Fig. 15 (b)). When the air leakage flow rate was decreased to $2.08 \times 10^{-3} \mathrm{~m}^{3} \mathrm{~s}^{-1}$, the gas porosities of the valves disappear (Fig. 15(c)). As the air leakage flow rate was continued to decrease, all of the three valves became underfilled (Fig. 15(d)), and the valve heads also had not the gas porosities, but some shrinkage porosities (Fig. 15(e)). Examining the corresponding mould filling simulation results as shown in Fig. 9, we also see good agreement between the predicted and experimental results, although the predicted critical air leakage flow rate $\left(6.33 \times 10^{-4} \mathrm{~m}^{3} \mathrm{~s}^{-1}\right)$ is somewhat lower than the experimental one $\left(2.08 \times 10^{-3} \mathrm{~m}^{3} \mathrm{~s}^{-1}\right)$. This divergence may be attributed to the fact that

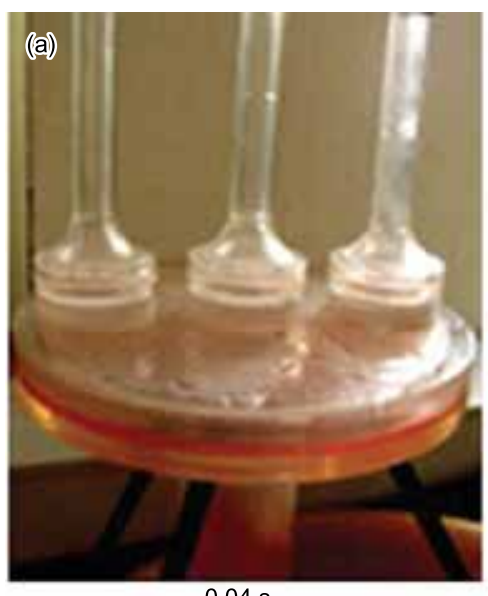

$0.04 \mathrm{~s}$

(d)

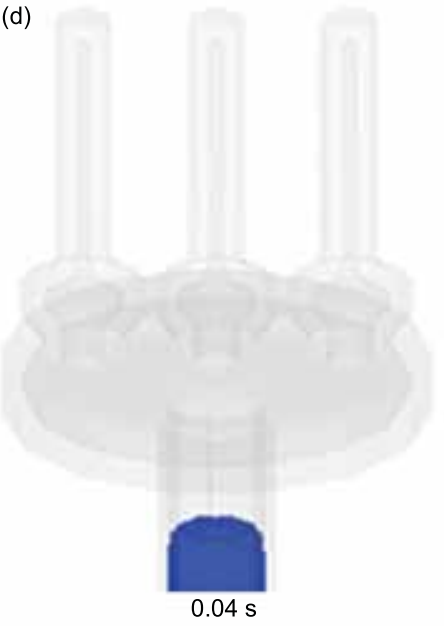

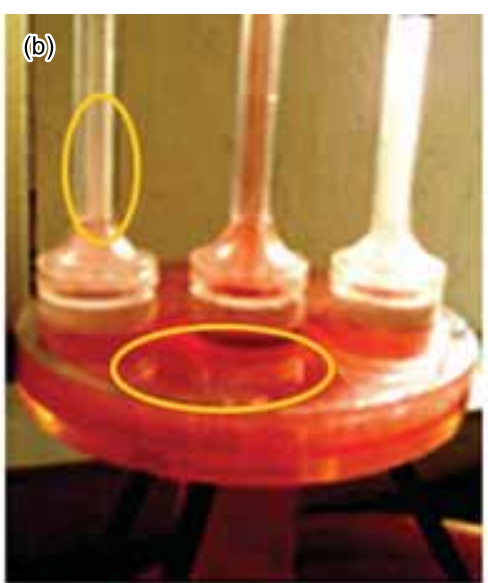

$0.16 \mathrm{~s}$

(e)

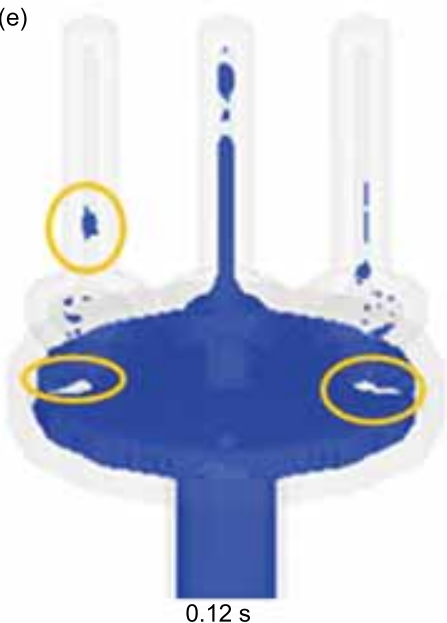

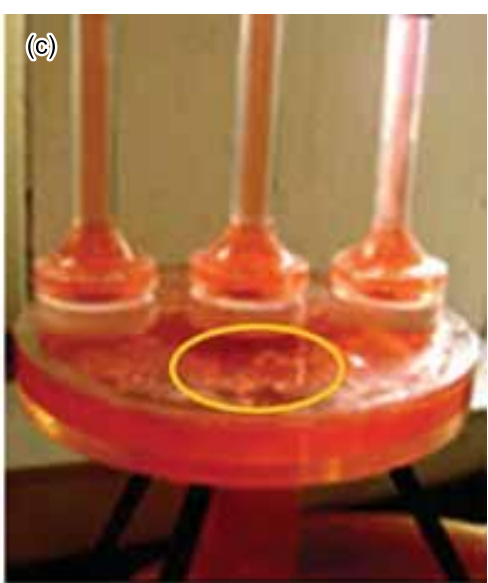

$0.28 \mathrm{~s}$

(f)

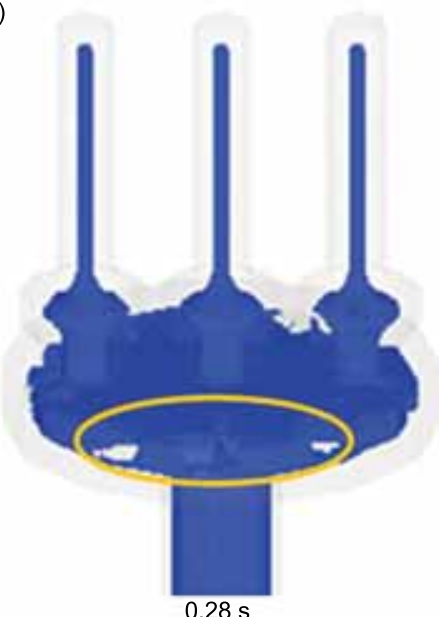

Fig. 13 Comparison of mould filling sequence between water analogue experiment of general suction casting $(\mathrm{a}-\mathrm{c})$ and its numerical simulation $(\mathrm{d}-\mathrm{f})$ at given times, water analogue experiment with $8 \mathrm{~mm}$ diameter vent under filling pressure difference of $11400 \mathrm{~Pa}$ 


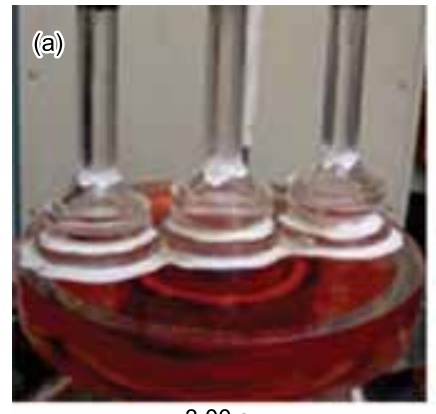

$3.00 \mathrm{~s}$

(d)

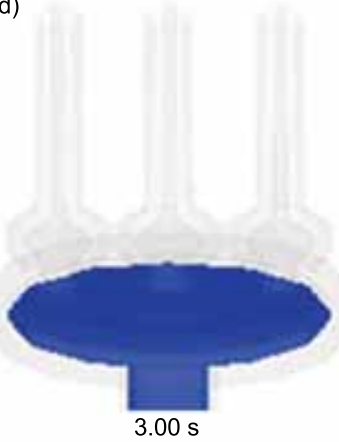

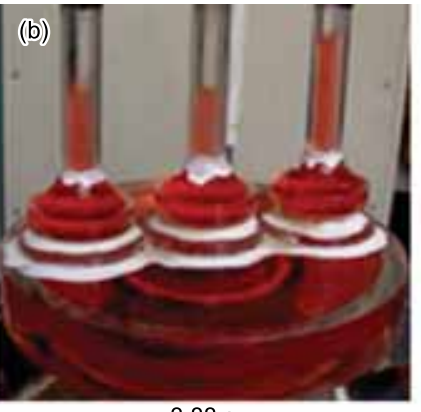

$3.88 \mathrm{~s}$

(e)

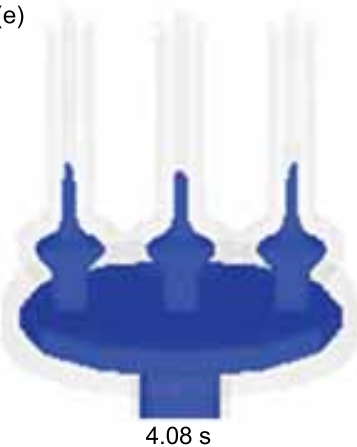

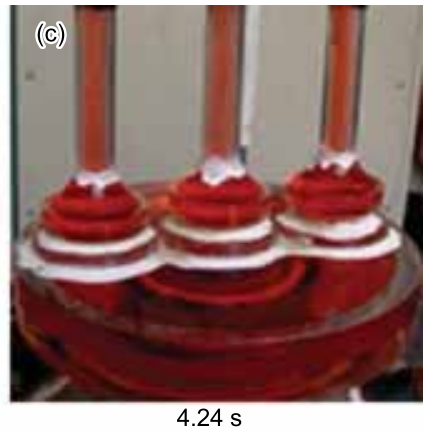

(f)

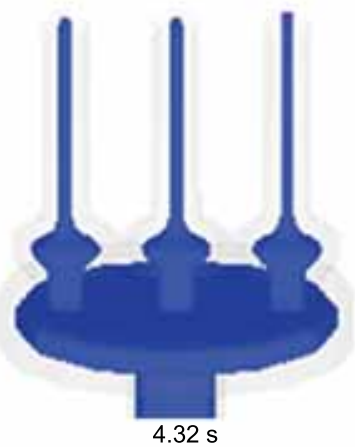

Fig. 14 Comparison of mould filling sequence between water analogue experiment of "air leakage" suction casting $(\mathrm{a}-\mathrm{c})$ and its numerical simulation $(\mathrm{d}-\mathrm{f})$ at given times, water analogue experiment with air leakage flow rate $1.94 \times 10^{-4} \mathrm{~m}^{3} \mathrm{~s}^{-1}$ under filling pressure difference of $50662.5 \mathrm{~Pa}$
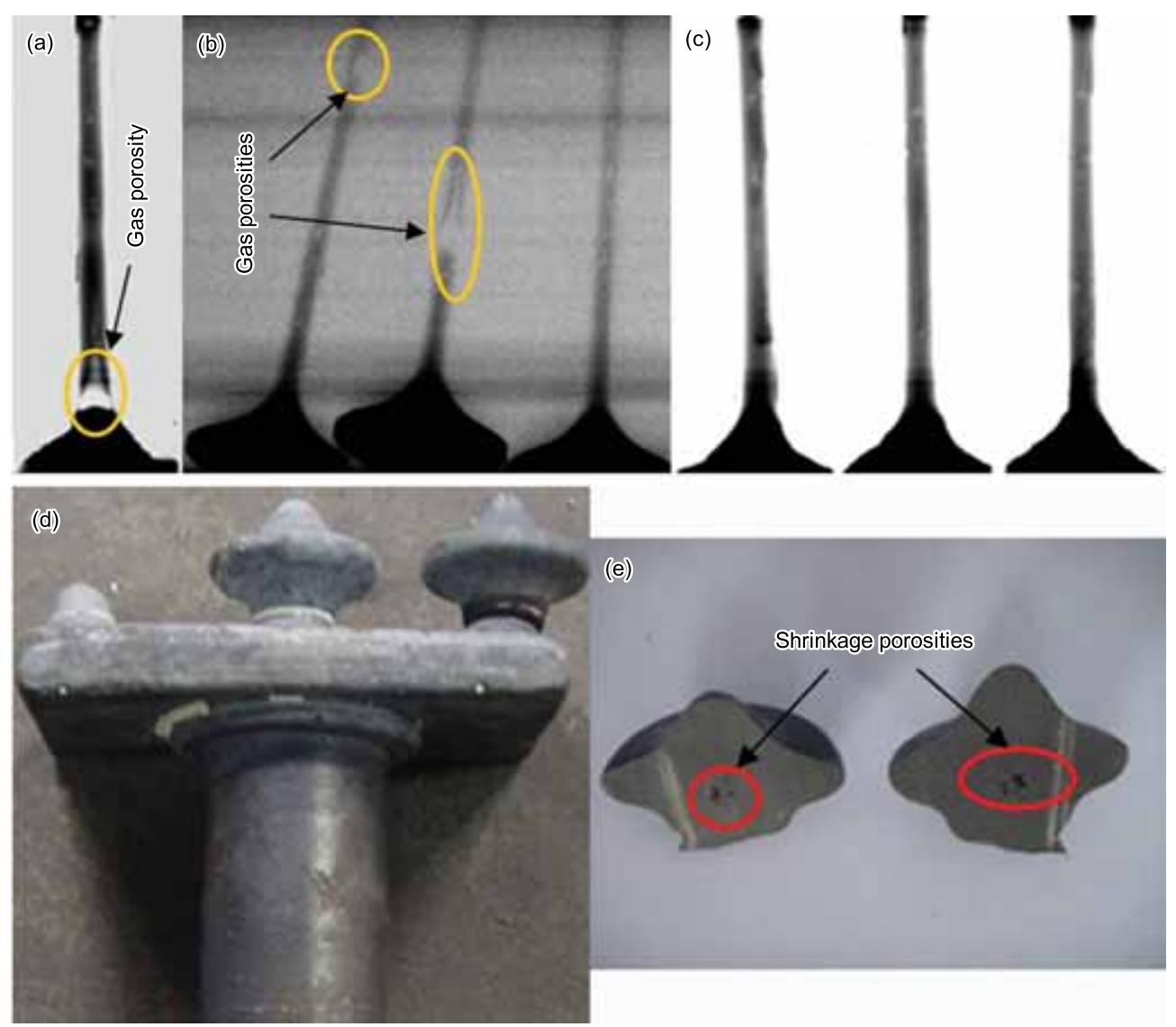

Fig. 15 X-ray radiography and middle vertical section inspections of automotive exhaust valves of $\gamma$-TiAl based alloys fabricated by general and "air leakage" suction casting: (a) general suction casting employing full-open ball valve of $0.008 \mathrm{~m}$ nominal diameter; (b) "air leakage" suction casting with $2.78 \times 10^{-3} \mathrm{~m}^{3} \mathrm{~s}^{-1}$ flow rate; (c) "air leakage" suction casting with $2.08 \times 10^{-3} \mathrm{~m}^{3} \mathrm{~s}^{-1}$ flow rate; (d, e) "air leakage" suction casting with $6.33 \times 10^{-4} \mathrm{~m}^{3} \mathrm{~s}^{-1}$ flow rate 
the TiAl molten metal in the mould filling simulation is assumed to be a Newtonian fluid of which the viscosity is a constant, but the viscosity of the molten metal in the real suction casting, which is a function of the strain rate and temperature, continues to increase as the mould filling proceeds, so under the same filling pressure difference profile, the smaller viscosity of the fluid in the mould filling simulation gives rise to a higher filling speed, more intensive surface turbulence and a smaller amount of heat loss, resulting in a lower critical air leakage flow rate and lower risk of misrun.

\subsection{Shrinkage porosities}

Based on the results of the suction casting experiments of TiAl automotive valves, the "air leakage" filling pressure difference control method with the air leakage flow rate of $2.08 \times 10^{-3} \mathrm{~m}^{3} \mathrm{~s}^{-1}$ and the mould with the tetragonal runner would continue to be applied in the solidification process modeling. The other casting parameters which had been given in section 2.2 were fixed. As discussed above, the appropriate pressure hold-up time was determined at first. Fig. 16 shows the effect of the pressure hold-up time on the final shapes of $\mathrm{TiAl}$ automotive valve castings. If the pressure hold-up time was too short, misrun occurred in the castings because the draining was performed too early and the castings did not solidified completely (Fig. 16(a)), whereas, if the pressure holdup time was too long, the weight of the molten metal drained back into the crucible was small, i.e., the utilization efficiency of the material was low although the castings solidified completely (Fig. 16(c)). The appropriate pressure hold-up time can trade off the casting integrity and the economical efficiency of the suction casting process. For the "air leakage" suction casting of TiAl automotive valves, the calculated pressure hold-up time was ascertain to be $73 \mathrm{~s}$ as seen in Fig. 16(b). Matching of the calculated and observed final shapes (Fig. 16(d)) of TiAl automotive valve castings is taken to be a sufficient indication of the accuracy of the solidification process modeling.

Next the shrinkage porosities formed during the solidification process were predicted using the ISOCHRONS function and the Niyama criteria function $\left(N_{\mathrm{c}}\right)$ which took value of $5 \times 10^{-2} \mathrm{~K}^{1 / 2} \mathrm{~s}^{1 / 2} \mathrm{~m}^{-1}$. In Fig. 17(a) and (b), it is seen that a small number of microporosities mounted along the central axes of the valve stems and a large macroporosity set down in the body center of the tetragonal runner. Temperature fields have a great influence on the potential microporosity locations, as illustrated in Fig. 18. The areas near the central axes of the valve stems (denoted by the cyan circles in Fig. 18(a)) tended to hold heat much longer than the rest of the part. As the solidification proceeded, the feeding paths connected to the ingates were cut off prematurely and then the microporosities were produced in those isolated areas (denoted by the cyan circles in Fig. 18(b) and (c)). The reason why the macroporosity formed in the body center of the tetragonal runner was the same to that of the microporosities, which is evident from Fig. 16(b) and (c).

The experimental observations and their schematic illustrations of the shrinkage porosities, macroporosities and microporosities, are shown in Fig. $17(\mathrm{c})$ and (d). When they are compared to the simulated results with the same casting parameters, satisfactory consistency is observed. It is generally agreed that shrinkage porosity result in a decrease of casting mechanical properties ${ }^{[38]}$, so future efforts will concentrate at finding out the strategies to eliminate the porosity defects.
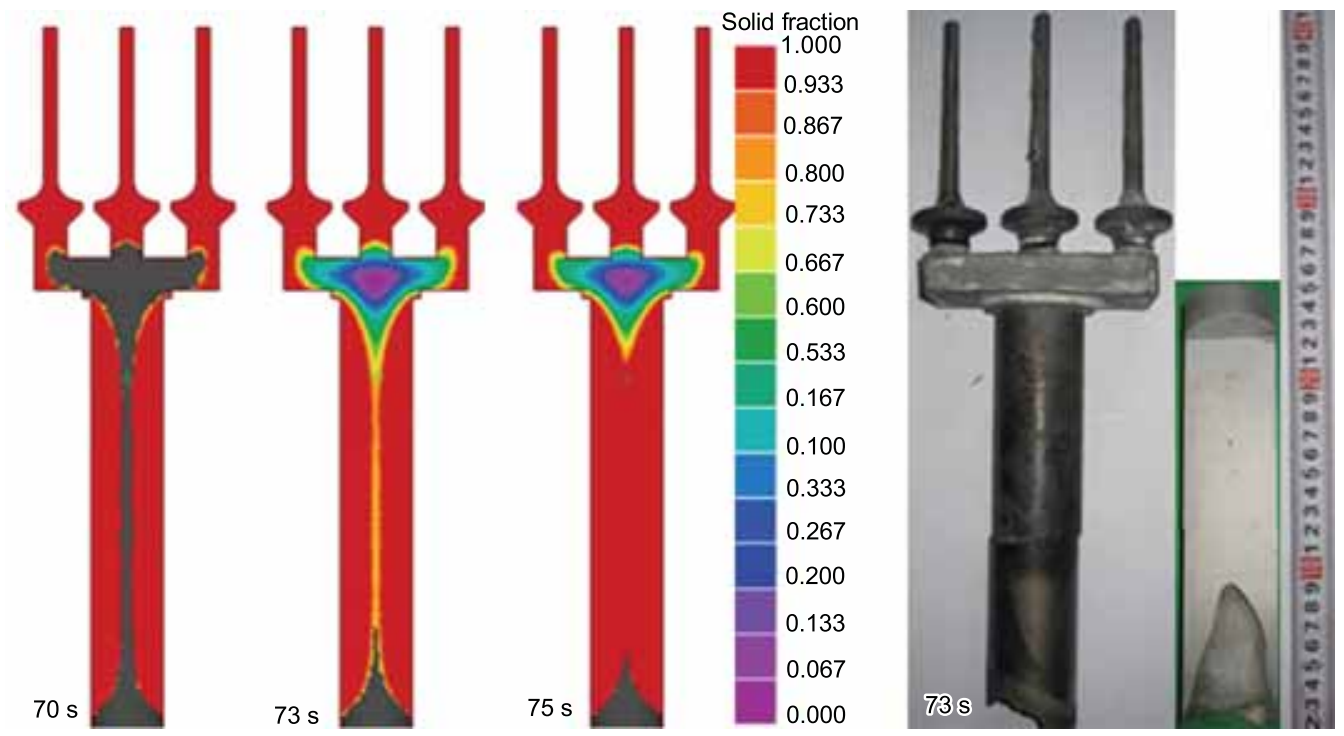

Fig. 16 Predicted final shapes of TiAl automotive valve castings fabricated by "air leakage" suction casting with different pressure hold-up times and the experimental verification (pouring temperature is 1953 $\mathrm{K}$, preheated temperature of investment mould is $873 \mathrm{~K}$, filling pressure difference is $80000 \mathrm{~Pa}$, air leakage flow rate is $2.08 \times 10^{-3} \mathrm{~m}^{3} \mathrm{~s}^{-1}$, and the mould with the tetragonal runner) 


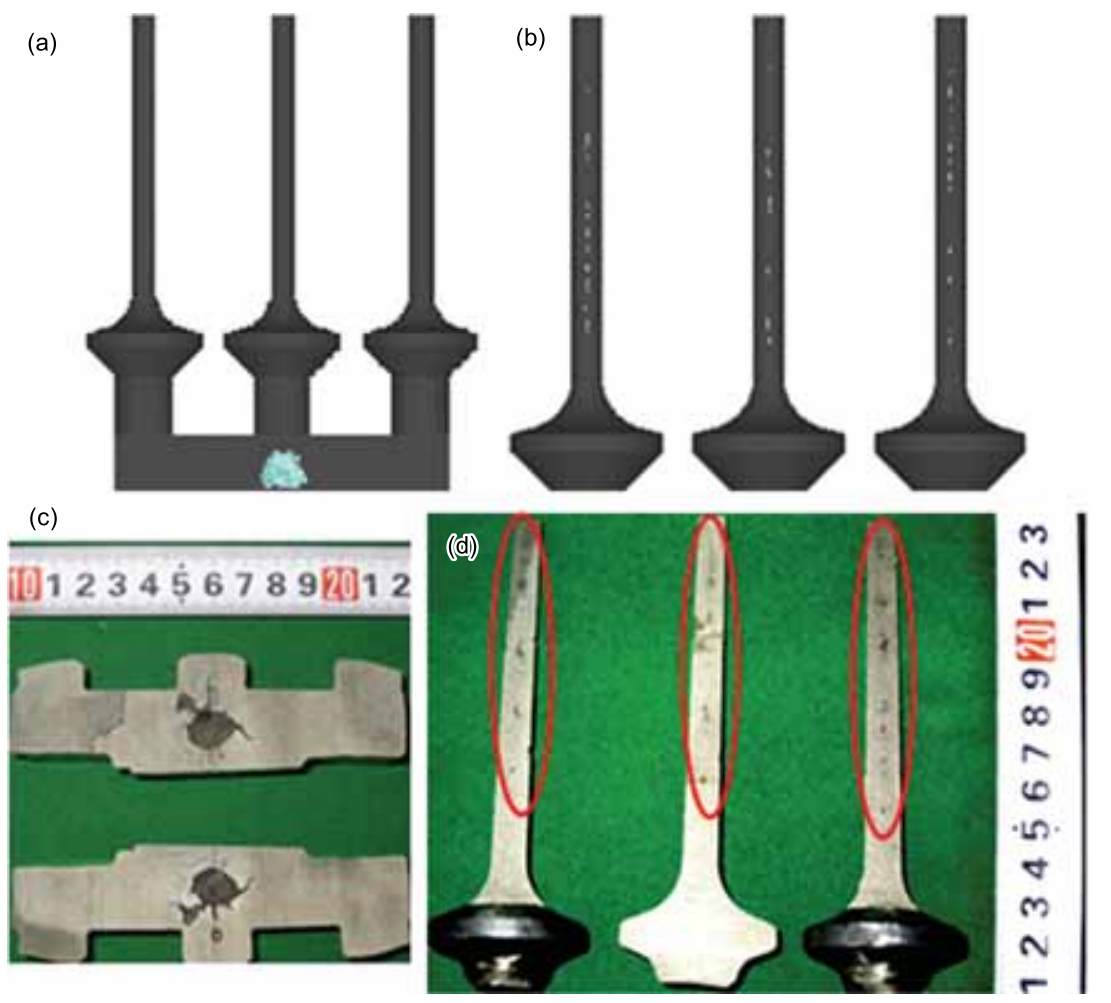

Fig. 17 Predicted potential shrinkage porosity locations of TiAl automotive valve castings fabricated by "air leakage" suction casting with pressure hold-up time of $73 \mathrm{~s}$ and their experimental verification: (a) macroporosity of solidification process simulation; (b) microporosities of solidification process simulation; (c) macroporosities of "air leakage" suction casting; (d) microporosities of "air leakage" suction casting (other casting parameters is the same as Fig. 16 lists, green areas in Fig.17 (a) and (b) represent macroporosities and microporosities

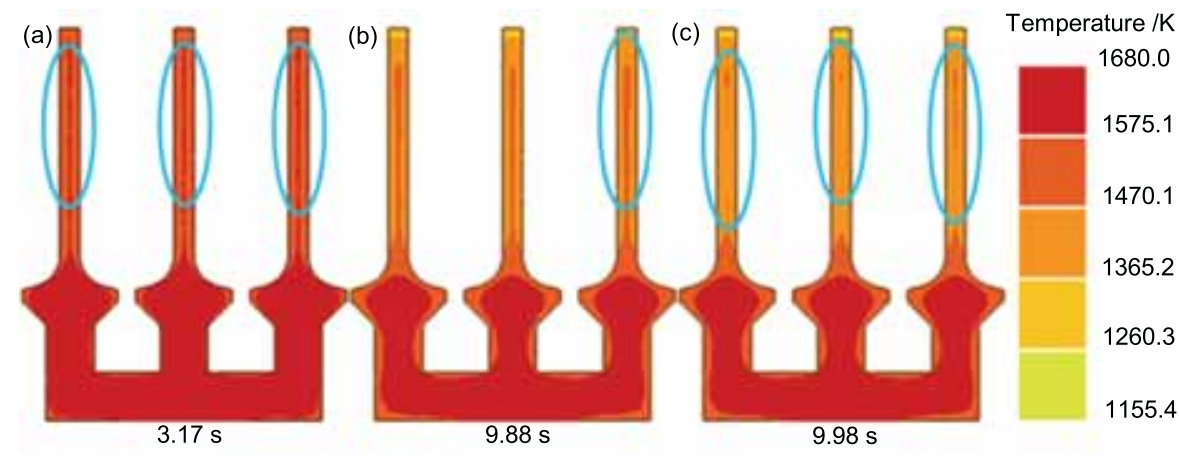

Fig. 18 Temperature field simulation results of TiAl automotive valves fabricated by "air leakage" suction casting with pressure hold-up time of $73 \mathrm{~s}$

\section{Conclusions}

The mould filling and solidification process of TiAl automotive valves manufactured by suction casting have been simulated. From the present work, the following conclusions can be drawn.

(1) The flow fields during the mould filling process and the temperature fields during the solidification process are obtained, and three kinds of potential defects including the gas bubbles and surface air entrainment occurred in the mould filling process and the shrinkage porosities formed in the solidification process are predicted.
(2) Through changing the filling pressure difference control methods from the general suction casting to the "air leakage" suction casting and reducing the air leakage flow rates, the gas bubbles are eliminated effectively, and the surface air entrainment attenuate dramatically. With resort to the mould with the tetragonal runner, the surface air entrainment decrease to the lowest level.

(3) The optimized casting parameters for the "air leakage" suction casting of TiAl automotive valves employed the mould with the tetragonal runner are found that pouring temperature is $1953 \mathrm{~K}$, mould preheated temperature is $873 \mathrm{~K}$, filling pressure dif- 
ference is $80000 \mathrm{~Pa}$, air leakage flow rate is $2.08 \times$ $10^{-3} \mathrm{~m}^{3} \mathrm{~s}^{-1}$ and pressure hold-up time is $73 \mathrm{~s}$.

(4) The predicted mould filling sequences and shrinkage porosities bear excellent correspondence with the ones directly observed in water analogue and suction casting experiments. It can be concluded that the numerical algorithm used in this work can simulate the main features of the mould filling and solidification process during suction casting.

\section{Acknowledgements}

The authors would like to thank Dr. Paixian FU at the Institute of Metal Research, CAS and Dr. Le ZHOU of the Material Science and Engineering Department of Shenyang University of Technology for simulation software support.

\section{REFERENCES}

[1] K. Gebauer, Intermetallics, 14 (2006) 355.

[2] W.E. Dowling, W.T. Donlon and J.E. Allison, in: I. Baker, S. Hanada, J. Horton, R.D. Noebe and D.S. Schwartz (Eds.), High-Temperature Ordered Intermetallic Alloys VI: Vol. 364 (MRS Proceedings), Materials Research Society, Pittsburgh, PA, 1995, pp.757.

[3] A.W. Sommer and G.C. Keijzers, in: Y.W. Kim, H. Clemens, and A.H. Rosenberger (Eds.) Gamma Titanium Aluminides 2003, TMS, Warrendale, PA, 2003, p.3.

[4] S.E. HartfieldWunsch, A.A. Sperling, R.S. Morrison, W.E. Dowling and J.E. Allison, in: F. Appel, J.D.H. Paul, M. Oehring, Gamma Titanium Aluminides, Wiley-VCH , San Francisco, CA, 1995, p.41.

[5] Y.W. Kim and D.M. Dimiduk, JOM 43 (1991) 40.

[6] F. Appel and R. Wagner, Mater. Sci. Eng. R 22 (1998) 187.

[7] H. Clemens and H. Kestler, Adv. Eng. Mater. 2 (2000) 551.

[8] M. Nazmy, C. Noseda, M. Staubli and B. Phillipsen, in: R.H. Jones and N.S Stoloff (Eds.), Processing and Design Issues in High Temperature Materials, TMS, Warrendale, PA, 1996, p.159.

[9] W. Smarsly, H. Baur, G. Glitz, H. Clemens, T. Khan and M. Thomas, in: K. J. Hemker, Minerals Metals and Materials Society Structural Materials Division, International Symposium on Structural Intermetallics 2001 Jackson Hol (Eds.), Structural Intermetallics 2001, third ed., TMS, Warrendale, PA, 2001, p. 25 .

[10] G.D. Chandley, AFS Trans. 84 (1976) 37.

[11] G.D. Chandley and D.L. Cargill, AFS Trans. 98 (1990) 413.

[12] S. Kashiwai, I. Ohnaka, A. Kimatsuka, T. Kaneyoshi, T. Ohmichi and J. Zhu, Int. J. Cast Met. Res. 18 (2005) 144.

[13] S.R. Giese and L. Dix, AFS Trans. 107 (1999) 217.

[14] L. Yuan, J. Yang, S.M. Xiong and B.C. Liu, Int. J. Cast Met. Res. 21 (2008) 401.
[15] P.X. Fu, X.H. Kang, Y.C. Ma, K. Liu, D.Z. Li and Y.Y. Li, Intermetallics 16 (2008) 130.

[16] Y.C. Wang, D.Y. Li, Y.H. Peng and X.Q. Zeng, Int. J. Adv. Manuf. Technol. 32 (2007) 257.

[17] M.R. Barkhudarov and C.W. Hirt, in: M. Cross, J Campbell and J.E. Campell (Eds.), Modeling of Casting, Welding and Advanced Solidification Processes VII, TMS, Warrendale, PA, 1995, p.935.

[18] A.H.G. Isfahani and J.M. Brethour, The FluidStructure Interaction and Thermal Stress Evolution Models in FLOW-3D, Flow Science, Inc., 2009.

[19] M.C. Carter, S. Palit and M. Littler, CastExpo '10, NADCA, Orlando, Florida, 2010.

[20] T. Yoshimura, K. Yano, T. Fukui, S. Yamamoto, S. Nishido, M. Watanabe and Y. Nemoto, Proceedings of 10th Asian Foundry Congress, Nagoya, Japan, 2008.

[21] J.H. Kuo and W.S. Hwang, Modell. Simul. Mater. Sci. Eng. 8 (2000) 583.

[22] C. Xiong, Y.C. Ma, B. Chen, K. Liu and Y.Y. Li, Acta Metall. Sin. 47 (2011) 1408. (in Chinese)

[23] P. Kobryn and S. Semiatin, Metall. Mater. Trans. B 32 (2001) 685.

[24] L. Biasetto, M. Manzolaro and A. Andrighetto, Eur. Phys. J. A 38 (2008) 167.

[25] D.J. Browne and K. Sayers, in: M. Cross, J. Campbell and J.E. Campell (Eds.), Modeling of Casting, Welding and Advanced Solidification Processes VII, TMS, Warrendale, PA, 1995, p.441.

[26] D.J. Browne and D. O'Mahoney, Metall. Mater. Trans. A 32 (2001) 3055.

[27] C.D. Anderson, W.H. Hofmeister and R.J. Bayuzick, Metall. Trans. A 24 (1993) 61.

[28] A.S. Sabau, Int. J. Cast Met. Res. 19 (2006) 188.

[29] W.M. Gao, L.X. Kong and P.D. Hodgson, 9th International Conference on Metal Forming (Metal Forming 2002), Birmingham, England, 2002, p.170.

[30] K.C. Mills, Recommended values of thermophysical properties for selected commercial alloys, Woodhead publishing Ltd and ASM International, Cambridge, England, 2002, p.132.

[31] P.F. Paradis, T. Ishikawa and S. Yoda, Int. J. Thermophys. 23 (2002) 825.

[32] C. Cagran, B. Wilthan, G. Pottlacher, B. Roebuck, M. Wickins and R.A. Harding, Intermetallics 11 (2003) 1327.

[33] R.A. Harding, R.F. Brooks, G. Pottlacher and J. Brillo, in: Y.W. Kim, H. Clemens, and A.H. Rosenberger (Eds.) Gamma Titanium Aluminides 2003, TMS, Warrendale, PA, 2003, p.75.

[34] I. Egry, R. Brooks, D. Holland-Moritz, R. Novakovic, T. Matsushita, E. Ricci, S. Seetharaman, R. Wunderlich and D. Jarvis, Int. J. Thermophys. 28 (2007) 1026.

[35] D. Au, S. Cockcroft and D. Maijer, Metall. Mater. Trans. A 33 (2002) 2053.

[36] K. Heames and G.H. Geiger, Proceedings of the 26th Annual Technical Meeting of the Investment Casting Institute, USA, 1978, 5d:1.

[37] H. Saari, D.Y. Seo, J. Blumm and J. Beddoes, J. Therm. Anal. Calorim. 73 (2003) 381.

[38] C. Pequet, M. Gremaud and M. Rappaz, Metall. Mater. Trans. A 33 (2002) 2095. 